\title{
LA ADOPCIÓN DE ACUERDOS DE LA ASAMBLEA GENERAL DE LA COOPERATIVA MEDIANTE VOTACIÓN SECRETA
}

\section{Joaquim Castañer Codina}

Profesor de Derecho Mercantil

Universitat Pompeu Fabra

http://orcid.org/0000-0003-2761-4216

\section{RESUMEN}

El derecho de voto de los socios en la asamblea general es un elemento configurador básico de las cooperativas. Una de las formas en que puede ser expresado este derecho es la llamada votación secreta. Esta modalidad de voto se produce cuando no es posible conocer el sentido del voto de los socios. La votación secreta se contempla de forma expresa, con mayor o menor alcance, en todas las leyes de cooperativas de nuestro país, estatal y autonómicas. Sin embargo, la regulación presenta muchas diferencias y disparidades que no tienen justificación. El presente trabajo pretende hacer un análisis crítico de esta modalidad de voto, a partir de su regulación en aquellas leyes de cooperativas.

PALABRAS CLAVE: Cooperativa, órganos sociales, asamblea general, acuerdos sociales, voto secreto.

CLAVES ECONLIT / ECONLIT DESCRIPTORS: P13, K12, K22.

Cómo citar este artículo/How to cite this article: CASTAÑER CODINA, Joaquim: "La adopción de acuerdos de la asamblea general de la cooperativa mediante votación secreta", CIRIEC-España, Revista Jurídica de Economía Social y Cooperativa, n³ 38, 2021, pp. 169-215. DOI: $10.7203 /$ CIRIEC-JUR.38.17740 
(pp. 169-215)

\section{THE ADOPTION OF AGREEMENTS OF THE GENERAL MEETING OF THE COOPERATIVE THROUGH SECRET VOTING}

\section{EXPANDED ABSTRACT}

Spanish cooperative laws are very sparing when it comes to regulating the form of voting in the adoption of resolutions of the general assembly. This scarcity of rules is due to a fully conscious choice of the legislator: it is the cooperative itself that, by virtue of the principle of autonomy of the will, decides which voting mechanisms will be used in the adoption of agreements.

Among the few regulations that we can find in this matter, there are those that require that certain agreements be made by secret vote of the partners. The ratio of this requirement is usually the need to guarantee the freedom and independence of vote of the member when certain agreements are made that especially affect the position of economic dependence that he maintains with the cooperative. It must be remembered the great impact, mainly economic, that the cooperative can have on the member's personal and family life (e.g., an associated work cooperative that is the source of their livelihood or a housing cooperative that must provide them with a decent housing). In this sense, the secret ballot is directly connected with the double condition of member and user that is typical of the mutualism that characterizes the cooperative.

These rules on secret ballot provided in the various cooperative laws can be divided into three groups.

In the first place, we have the rules that require that certain specific agreements be adopted in any case by secret ballot (secret ballot by legal provision). The most important are, on the one hand, the agreements for the election and removal of the members of the corporate bodies as well as the exercise of liability action against them. And, on the other, some agreements related to the acquisition and loss of membership (and, especially, the decision to expel him from the cooperative).

Second, we mention the rules that give the cooperative's bylaws the power to expand the agreements that the general assembly must adopt by secret ballot (secret ballot by statutory provision). The statutes cannot suppress the legal assumptions of secret voting, unless the law expressly allows it. But they can add other agreements that will have to be adopted by secret ballot, as well as subject these new cases of secret ballot to conditions. On the contrary, the other internal regulations of the cooperative lack this power. 
(pp. 169-215)

And, as a last class of rules, we point out those that attribute to a percentage of votes (or, according to the law, of partners) the right to demand the adoption of agreements by secret ballot, and that also usually enable the statutes to introduce precautions to avoid the abusive exercise of this right (secret ballot requested). It is a minority right that state law attributes to $10 \%$ of the votes present and represented in the assembly, unless the statutes lower this percentage. The regional laws also recognize this right, although some establish different percentages or computational bases. In principle, this request can be made with respect to any type of agreement, unless otherwise provided by law or statute. The statutes can also introduce precautions to prevent and avoid the abusive exercise of this right, among which it is worth highlighting that only one request for a secret vote can be promoted in each assembly session.

One of the problems with secret suffrage is how to make its exercise compatible with some of the rights of the partners that, as a general rule, require that the meaning of their vote be known. Specifically, the work refers to four different cases.

The first is how to determine which partners will be able to challenge the corporate resolutions adopted secretly, when active legitimacy is attributed only to those who have not voted in favor of the agreement. In the Spanish sphere, this issue has been resolved, in general terms, by requiring that the partner who wants to challenge discloses the meaning of his vote in the minutes of the meeting or within the following 48 hours. The partner must choose: either he reveals the meaning of his vote in order to challenge the agreement, or he keeps his vote hidden but will no longer be entitled to challenge.

The second case refers to the problems posed by secret voting when there is plural or fractional vote in the cooperative or, in general, the principle that each member has only one vote is not followed. It is evident that the breaking of this principle makes secret voting difficult but does not prevent it, since these difficulties are often technical-organizational in nature and, therefore, can be overcome. In any case, state law incorporates a double provision that affects this issue. On the one hand, providing that the members holding plural votes may renounce them and exercise only one vote. On the other, allowing the statutes to regulate cases in which equal voting will be imperative.

As a third case, we study the effects of the secret ballot in the adoption of resolutions that activate the right of the member to cause justified withdrawal from the cooperative. First of all, it should be noted that none of the legal agreements that allow qualifying the withdrawal as justified must be adopted by secret ballot. This means that the coincidence can only occur if the statutes extend the cases of secret ballot and / or the causes of justified voluntary withdrawal. And, in this case, the logical thing is that these same statutes foresee how to 
make the secret ballot compatible with the identification of those entitled to exercise the right of justified withdrawal.

Finally, a fourth scenario that we consider is the impact that the secret vote has on the agreements where some partner must abstain due to incurring in conflict of interest. $0 \mathrm{n}$ the one hand, the secret nature of the vote should not prevent the identification of the conflict of interest situation before the voting takes place and, once this situation is noticed, deny the exercise of the vote to the partner involved in this conflict. On the other hand, if this partner were to vote, the democratic principle makes it difficult for his vote to become decisive in reaching the agreement and, even if it were, mechanisms can be found to deactivate the inconveniences that the secret ballot presents.

In sum, we conclude that these cases may make it difficult to exercise the secret ballot but they do not really prevent it. However, in some of them it is convenient to alleviate the obstacles that may arise by introducing certain precautions in the bylaws of the cooperative.

KEYWORDS: Cooperative, corporate bodies, general meeting, social agreements, secret vote. 


\section{SUMARIO}

1. Forma de emisión del voto en la asamblea general de la cooperativa. 2. Regulación del voto secreto en la asamblea general. 2.1. Panorámica general. 2.2. Votación secreta por disposición legal. 2.3. Votación secreta por disposición estatutaria. 2.4. Votación secreta rogada. 3. Ratio del voto secreto. 4. Incidencia del carácter secreto del voto sobre el ejercicio de (ciertos) derechos sociales. 4.1. Impugnación de acuerdos adoptados mediante votación secreta. 4.2. Carácter secreto del sufragio y voto plural. 4.3. Acuerdos que dan lugar al derecho a causar baja justificada de la sociedad. 4.4. Deber de abstención del socio en conflicto de intereses y voto secreto. Bibliografía.

\section{Forma de emisión del voto en la asamblea general de la cooperativa}

Las leyes de cooperativas ${ }^{1}$ son muy parcas a la hora de regular la forma o modalidad de emisión del voto en la adopción de acuerdos de la asamblea general. En términos generales, puede decirse que solamente incluyen algunas disposiciones relativas a los casos en que la votación habrá de ser secreta y otras referentes al ejercicio del derecho de voto a distancia (por correo o de forma telemática) ${ }^{2}$.

1. En el presente trabajo se citarán a menudo las diversas leyes de cooperativas de nuestro país, que serán abreviadas de la siguiente forma: Ley 5/1998, de 18 de diciembre, de Cooperativas de Galicia [LCGal]; Ley 4/1999, de 30 de marzo, de Cooperativas de la Comunidad de Madrid [LCCMad]; Ley 27/1999, de 16 de julio, de Cooperativas [LCoop]; Ley 4/2001, de 2 de julio, de Cooperativas de La Rioja [LCRio]; Ley 4/2002, de 11 de abril, de Cooperativas de la Comunidad de Castilla y León [LCCLeón]; Ley 1/2003, de 20 de marzo, de Cooperativas de las Illes Balears [LCIBal]; Ley 8/2006, de 16 de noviembre, de Sociedades Cooperativas de la Región de Murcia [LCMur]; Ley Foral 14/2006, de 11 de diciembre, de Cooperativas de Navarra [LFCNav]; Ley del Principado de Asturias 4/2010, de 29 de junio, de Cooperativas [LCAst]; Ley 11/2010, de 4 de noviembre, de Cooperativas de Castilla-La Mancha [LCCMancha]; Ley 14/2011, de 23 de diciembre, de Sociedades Cooperativas Andaluzas [LSCAnd]; Ley 6/2013, de 6 de noviembre, de Cooperativas de Cantabria [LCCan]; Decreto Legislativo 2/2014, de 29 de agosto, del Gobierno de Aragón, por el que se aprueba el texto refundido de la Ley de Cooperativas de Aragón [TRLCAr]; Decreto Legislativo 2/2015, de 15 de mayo, del Consell, por el que se aprueba el texto refundido de la Ley de Cooperativas de la Comunidad Valenciana [TRLCCVal]; Ley 12/2015, de 9 de julio, de Cooperativas de Cataluña [LCCat]; Ley 9/2018, de 30 de octubre, de Sociedades Cooperativas de Extremadura [LSCExt]; Ley 11/2019, de 20 de diciembre, de Cooperativas de Euskadi [LCEusk]. En fin, en ocasiones se hará referencia también al Reglamento (CE) no 1435/2003 del Consejo, de 22 de julio de 2003, relativo al Estatuto de la Sociedad Cooperativa Europea [RSCE].

2. En relación con el voto por correo, MORILLAS JARILLO \& FELIÚ REY (2002:259), señalan que se trata de la "modalidad definitiva del "voto secreto"». Sin embargo, otros autores - p.ej., NIUTTA (1994:880), BALZANO (1997:779) o FIMMANÓ (2002:708)-, precisan que el voto por correo es una modalidad de 
No obstante, esta escasez de normas obedece a una opción totalmente consciente del legislador: que sea la propia cooperativa quien, en virtud del principio de autonomía de la voluntad, decida qué modalidades o mecánicas de voto se utilizarán en la adopción de acuerdos. Naturalmente, esta facultad auto-organizativa de la cooperativa habrá de respetar las (pocas) reglas imperativas que sobre forma de emisión del voto contenga la ley de cooperativas que sea aplicable.

A partir de estas afirmaciones, podemos formular los siguientes tres principios o reglas generales.

En primer lugar, que salvo disposición legal en contrario, es la propia cooperativa la que decide la forma de emisión del voto en la asamblea general (p.ej., si se hará a mano alzada, por aclamación, mediante llamamiento nominal a cada persona con derecho de voto, de forma secreta, etc. $)^{3}$. En principio, las modalidades y mecánicas de voto pueden establecerse en los estatutos de la cooperativa o, de existir, en su reglamento de régimen interno o, incluso, en el reglamento de la asamblea general. Y, en caso de que todos estos textos guarden silencio, la potestad de decidir la modalidad de voto a utilizar para cada votación ha de atribuirse a la propia asamblea general o a su presidente ${ }^{4}$.

En segundo término, que las reglas legales sobre emisión del voto que se prevén en las leyes de cooperativas (p.ej., sobre votación secreta o voto por correo) han de considerarse imperativas, salvo que otra cosa disponga o se desprenda de la propia ley. En efecto, si el legislador ha optado en esta materia por el principio de intervención mínima, es lógico entender que, por regla general, las normas que formula han de ser necesariamente respetadas ya que pretenden alcanzar unos objetivos (p.ej., protección de la libertad e independencia del criterio del socio en la votación secreta, tutela de la procedencia y autenticidad del voto que se realice por medios telemáticos, etc.) cuyo

voto abierto. Igualmente, GENNARI (2003:874), sostiene que el voto mediante medios de telecomunicación es objetivamente incompatible con cualquier forma de voto secreto. En realidad, creemos que tanto el voto por correo como el voto telemático puede ser abierto o secreto en función de si se ha hecho o no pública la identidad del socio que lo emite y su contenido, más allá de la verificación (interna) de que el sufragio proviene efectivamente de una de las personas con derecho de voto y que se ha ejercido con todas las cautelas y formalidades exigidas.

3. En Italia, donde ha sido discutida la posibilidad de adoptar acuerdos mediante votación secreta, un sector doctrinal se ha apoyado en el principio de libertad de forma en la emisión de voto para sostener su admisibilidad [p.ej., MASCHIO (1972:982) o ASQUINI (1970:500)], aunque también hay otro sector que rechaza que este principio sustente la viabilidad del voto secreto [vid. NIUTTA (1994:870), TASSINARI (1994:501) o PETRELLI (2005:7)].

4. Vid. PAZ CANALEJO (1990:482) o UCELAY URECH (1997:1352). Es evidente que, en caso de discrepancias, la asamblea general puede dejar sin efecto la decisión sobre modalidad de voto adoptada por su presidente. 
cumplimiento no puede ser confiado por entero a la autonomía de la voluntad de la cooperativa.

Y, en tercer y último lugar, la combinación del principio de autonomía de la voluntad como regla general y del principio de intervención mínima del legislador, lleva a la conclusión de que esas normas legales imperativas han de ser interpretadas restrictivamente. En otras palabras, los límites que la ley establece a la autonomía de la voluntad de la cooperativa con relación a la modalidad o forma de ejercicio del voto (p.ej., imponiendo para ciertos acuerdos la votación secreta, exigiendo que se garantice la confidencialidad del voto telemático, etc.) no pueden extenderse más allá de los estrictos términos legales en que están formulados. Otra solución supondría cercenar o restringir indebidamente el principio general de auto-organización de la cooperativa que rige en esta materia.

\section{Regulación del voto secreto en la asamblea general}

\subsection{Panorámica general}

En la regulación actualmente vigente, lo primero que debemos destacar es que tanto la ley de cooperativas estatal como las diversas leyes autonómicas contienen, sin excepción, algún precepto en el que se prevé el uso de la votación secreta para la adopción de (ciertos) acuerdos en la asamblea general ${ }^{5}$. Y, en términos generales, puede decirse que prácticamente todas estas leyes incluyen tres tipos de normas:

a) En primer lugar, exigen que ciertos acuerdos concretos sean adoptados siempre mediante voto secreto (votación secreta por disposición legal).

b) En segundo término, otorgan a los estatutos de la cooperativa la facultad de ampliar los acuerdos que la asamblea general deberá adoptar mediante votación secreta (votación secreta por disposición estatutaria).

c) Y, por último, atribuyen a un porcentaje de votos (o, según las leyes, de socios) el derecho a solicitar la adopción de acuerdos mediante votación secreta (votación

5. No sucede lo mismo en el Reglamento de la Sociedad Cooperativa Europea (RSCE), en el que no existe previsión alguna acerca del voto secreto en la adopción de acuerdos. El mismo silencio guarda la normativa reguladora de las sociedades de capital. Sin embargo, la doctrina sostiene, en términos generales, la posibilidad de utilizar la votación secreta, aunque reconoce que este sistema «suscita problemas por ser difícil de controlar el número de votos de cada votante y porque dificulta la legitimación de los disidentes a efectos de impugnación de los acuerdos» (URÍA, MENÉNDEZ \& MUNOZ PLANAS, 1992:163) o, yendo incluso más allá, considera que "rara vez ésta podrá reputarse viable habida cuenta de que, aunque el voto se emita en sobre cerrado, en él deberá de identificarse el emisor para poder determinar el número de votos que le corresponden en razón del número de participaciones sociales que le pertenezcan» (CAICOYA CORES, 2017:1149). 
secreta rogada), habilitando en ocasiones expresamente a los estatutos para que introduzcan cautelas para evitar el ejercicio abusivo de tal derecho.

Al margen de estas normas, también es habitual que las leyes de cooperativas aclaren la legitimación para impugnar los acuerdos adoptados mediante votación secreta que sean anulables (p.ej., art. 31.4 LCoop) ${ }^{6}$. En fin, otras normas relativas al voto secreto solo aparecen, esporádicamente, en alguna ley de cooperativas o en su desarrollo reglamentario, como es el caso de la emisión de esta modalidad de voto cuando se celebra la asamblea por medios telemáticos [p.ej., art. 36.8.e) TRLCCVal] o de la forma de oponerse a un acuerdo adoptado mediante votación secreta a efectos del ejercicio del derecho de baja justificada de la sociedad (art. 97.3 LCCMancha).

\subsection{Votación secreta por disposición legal}

De la lectura de las leyes de cooperativas de nuestro país se desprende que los acuerdos en los que la normativa impone directamente que la votación de la asamblea sea secreta pueden dividirse en seis grandes grupos: uno, elección y cese de los miembros de los órganos sociales; dos, acuerdos relacionados con la adquisición y pérdida de la condición de socio; tres, ejercicio de la acción social de responsabilidad contra los miembros de los órganos sociales, así como su transacción y renuncia; cuatro, designación de los delegados en las asambleas bifásicas; cinco, acuerdos en que la asamblea revisa la negativa del consejo rector a dar información por considerar que pone en peligro los intereses de la cooperativa; y seis, en las cooperativas de trabajo asociado, la decisión de suspender la actividad de todos o parte de los socios trabajadores por causas económicas, técnicas, organizativas, de producción o derivadas de fuerza mayor.

Sin embargo, antes de exponer brevemente algunas ideas generales sobre cada uno de estos grupos, debemos efectuar dos aclaraciones: por un lado, no todas las leyes de cooperativas prevén los mismos supuestos de sufragio secreto sino que existen importantes diferencias entre ellas; por otro, prácticamente todas las leyes prevén el voto secreto para acuerdos incluidos en los tres primeros grupos ${ }^{7}$, en tanto que 
(pp. 169-215)

solamente algunas leyes aisladas exigen votación oculta para acuerdos comprendidos en los tres últimos bloques.

El primer grupo está compuesto por los acuerdos asamblearios de elección y cese de los miembros de los órganos sociales. En muchas de las leyes autonómicas podemos encontrar una primera disposición que prevé con carácter general el voto secreto en «la elección o revocación de los miembros de los órganos sociales» ${ }^{8}$, que viene luego complementada en preceptos particulares que reiteran -de un modo innecesario- la votación secreta en la elección de los administradores, interventores, miembros del comité de recursos, liquidadores o, esporádicamente, de los integrantes de otros órganos que voluntariamente puedan establecerse en la cooperativa'. En cambio, otras leyes carecen de aquella disposición general y se limitan a establecer el voto secreto para la elección de los miembros de cada uno de los órganos sociales de la cooperativa ${ }^{10}$. Esta fórmula plantea la cuestión de si se precisa voto secreto en la elección de los integrantes de otros órganos distintos, cuando para ellos no se ha previsto expresamente la fórmula del sufragio secreto ${ }^{11}$.

El segundo grupo comprende los acuerdos de la asamblea general de la cooperativa que resuelven recursos interpuestos contra las decisiones del órgano de administración relativas a la adquisición o a la pérdida de la condición de socio. En este grupo, el elenco de casos es variado incluyendo en prácticamente todas las leyes el acuerdo

8. Así sucede en los arts. 50.3 LCAst, 39.5 LCCan, 34.4 LCCLeón, 51.5.I LCCMancha, 41.6 LCIBal, 30.3 LSCAnd, 44.8 LSCExt y 34.5 TRLCAr.

9. Un ejemplo. El art. 30.3 LSCAnd establece que «[1] as votaciones serán secretas cuando tengan por finalidad [...] la elección o revocación de los miembros de los órganos sociales [...]», y luego la misma Ley dispone en el art. 38.2.I que "[1] os miembros del Consejo Rector serán elegidos de entre los socios y socias por la Asamblea General, en votación secreta», en el art. 43.1 que el comité técnico "[e] stará integrado, al menos, por tres miembros elegidos en votación secreta», y en el art. 81.1.I que "[1] as personas encargadas de la liquidación [...] serán nombradas por la Asamblea General que adopte el acuerdo de disolución, en votación secreta».

10. Es el caso precisamente de la LCoop en la que se prevé la votación secreta en la elección de consejeros (art. 34.1.I), interventores (art. 38.4), miembros del comité de recursos (art. 44.4) y liquidadores (art. 71.1). Vid. también los arts. 33.3.a) LCEusk y 31.1.b) LCGal.

11. Sin embargo, la duda no surge cuando la ley se limita a prever la designación de los administradores mediante votación secreta y remite, en la elección de los miembros de otros órganos, a lo establecido para el nombramiento de los administradores. Es el caso de la normativa valenciana, que en el art. 42.2.I establece que "[1]os miembros del consejo rector, las personas suplentes y, en su caso, el miembro o miembros del órgano de administración [...] serán elegidos por la asamblea general de la cooperativa [...] en votación secreta» y en el art. 52.1 dispone que "[s] e aplicarán las normas de esta ley sobre consejo rector a la elección» de los miembros de la comisión de recursos o en el art. 54.3 señala la aplicación supletoria a la comisión de control de la gestión, "[e]n lo no previsto en este artículo y en los estatutos sociales», de «las normas establecidas para el consejo rector». 
que conoce del recurso contra la expulsión de un socio ${ }^{12}$, en algunas menos los acuerdos que se adoptan revisando la decisión de admitir o rechazar a una persona como socio $^{13}$, y en unas pocas los acuerdos de baja obligatoria de los socios ${ }^{14}$ o por los que se deciden la calificación y efectos de una baja voluntaria ${ }^{15}$. Debido a esta diversidad normativa, queremos recordar que, en virtud de la interpretación restrictiva que hemos propugnado (supra apartado 1), no resulta posible la analogía legis para extender el voto secreto a supuestos de adquisición o pérdida de la condición de socio que no se hayan previsto de forma expresa.

Un tercer grupo incluye el acuerdo de ejercicio de la acción social de responsabilidad contra los miembros de los órganos sociales de la cooperativa, así como la decisión sobre su transacción y renuncia ${ }^{16}$. En este ámbito, creemos que la votación secreta ha de aplicarse a los tres acuerdos cuando la ley solo lo prevé para el primero (ejercicio de la acción social) porque «se olvida» de la existencia de los otros $\operatorname{dos}^{17}$. Y ello por cuanto no se trata en estos casos de interpretar extensivamente la norma sino de ajustar su aplicación a un conjunto homogéneo de acuerdos que están indisolublemente vinculados entre sí.

12. Vid. p.ej., arts. 18.5.II LCoop, 41.1.II LCAst, 29.4 LCCan, 36.2.b) LCCat, 22.2.III LCCMad, 32.3.II LCCMancha, 28.2.III LCEusk, 25.3.c).II LCGal, 32.2 LCIBal, 33.3 LCMur, 24.1.II LFCNav, 30.3 LSCAnd, 23.2.I TRLCAr. En algún caso, la votación secreta se prevé no solo para el acuerdo de expulsión sino para todos los supuestos de sanción por falta grave o muy grave [art. 32.3.c).II LSCExt] o, de un modo aún más general, para cualquier acuerdo sancionador [art. 25.3.c).II LCGal o, de forma más discutible, el legislador andaluz realiza esta ampliación por vía reglamentaria en el art. 22.3.b) del Decreto 123/2014, de 2 de septiembre, por el que se aprueba el Reglamento de la Ley 14/2011, de 23 de diciembre, de Sociedades Cooperativas Andaluzas].

13. En este caso, las leyes de cooperativas pueden dividirse en dos grupos. El primero está integrado por aquellas que prevén la votación secreta tanto para decidir sobre el recurso contra la admisión de un socio como decidir el recurso contra el rechazo a esta admisión (cfr. arts. 19.4.II y 19.5.II LCCMad, 20.4.II LCEusk y 20.5.II LCEusk, 19.2.II LCGal y 19.3 LCGal, 21.3.II LCRio y 21.4 LCRio, 17.4 TRLCAr y 17.5.II TRLCAr o 20.2.II TRLCCVal). El segundo grupo se compone de aquellas leyes que solo prevén la votación secreta en el acuerdo que revisa la decisión de denegar la admisión de un aspirante a socio (cfr. arts. 22.2 LCAst, 26.2 LCCMancha y 25.3 LSCExt).

14. Vid. art. 27.4.I LCCMancha y, en relación con la baja en las cooperativas de trabajo asociado, por causas económicas, técnicas, organizativas y de producción, arts. 149.1 LCAst, 27.4.I LCCMancha y 88.1 LSCAnd.

15. Vid. arts. 32.4 LCAst y 28.6.I LCCMancha.

16. Vid. arts. 50.3 LCAst, 39.5 LCCan, 34.4 LCCLeón, 51.5.I LCCMancha, 41.6 LCIBal, 30.3 LSCAnd, 44.8 LSCExt y 34.5 TRLCAr.

17. Vid. art. 29.3.a) LCCMad, que solamente prevé el ejercicio de la acción de responsabilidad contra los miembros de los órganos sociales, pero no menciona en ningún momento -ni en dicho precepto ni en ningún otro lugar de la ley- la posibilidad de su renuncia o transacción. 
El cuarto grupo se refiere a los acuerdos de las juntas preparatorias por los que se eligen a las personas que representarán a los socios en la asamblea de delegados ${ }^{18}$. Aquí hay que advertir que las leyes de cooperativas en que se exigía la votación secreta en estos acuerdos se han ido reduciendo ${ }^{19}$ de forma que en la actualidad solamente se prevé expresamente por cuatro de los legisladores autonómicos ${ }^{20}$.

En quinto lugar, los arts. 24.2.c).III LCCMad y 26.2.c).II TRLCCVal exigen la votación secreta para aquellos acuerdos en que la asamblea ordena suministrar una información que el consejo rector había denegado por considerar que ponía en peligro los intereses de la cooperativa. En ambos casos, la norma se enmarca en el derecho que tienen los socios, con anterioridad a la celebración de la asamblea o durante el transcurso de la misma, a ampliar la información que consideren necesaria con relación a los puntos contenidos en el orden del día. Pese a que esta información puede ser denegada por los administradores si su difusión pone en grave peligro los intereses de la cooperativa o debe mantenerse en reserva en cumplimiento de una obligación legal, la asamblea general podrá ordenar al consejo rector suministrar la información requerida. Este acuerdo de la asamblea será adoptado mediante votación secreta.

Finalmente, en último lugar, los arts. 125.3 LCCMancha, 150.3 LSCExt y 75.3 Decreto 123/2014 (Andalucía) establecen la votación secreta para la suspensión de los socios trabajadores de las cooperativas de trabajo asociado por causas económicas, técnicas, organizativas, de producción o derivadas de fuerza mayor. Este supuesto no puede incluirse dentro del segundo grupo, relativo a los acuerdos de adquisición o pérdida de la condición de socio, ya que la suspensión no produce de forma automá-

18. Esta elección no puede quedar comprendida en el primer grupo porque los delegados no tienen en ningún caso la consideración de órgano social. Por esta misma razón, no podemos aceptar que la votación secreta se extienda a la elección de otros sujetos como los componentes de la mesa de la asamblea general (vid. p.ej., art. 25.2 LCoop) o los socios que han de aprobar de forma diferida el acta de la asamblea (vid. p.ej., art. 29.2 LCoop). Sin embargo, en relación con este último supuesto, PAZ CANALEJO (1990:508-509), es partidario de que tales socios se elijan mediante votación secreta o, al menos, por un procedimiento imparcial o aleatorio como es el sorteo.

19. Es ejemplo de ello la propia legislación estatal de cooperativas pues mientras el art. 51.3 LGCoop 1987 disponía la votación secreta en los acuerdos de elección de delegados, la LCoop actual ya no la prevé, dejando que sean los estatutos de cada cooperativa los que, en su caso, la establezcan.

20. Vid. arts. 41.1.e) LCCan, 53.2.e) LCCLeón y 39.3.II LCGal. Un supuesto peculiar se encuentra en la normativa andaluza ya que la votación secreta en la elección de delegados no se prevé en la LSCAnd sino en el art. 33.3.II de su Reglamento de desarrollo, aprobado por Real Decreto 123/2014, de 2 de septiembre. En todos estos casos, la previsión legal de elección de delegados mediante votación secreta suele considerarse imperativa de modo que "[n] o cabe que los estatutos establezcan lo contrario» [SEDA HERMOSÍN (2002:416), en relación con la normativa andaluza]. 
tica esta pérdida, si bien en ambas normas se faculta a los socios suspendidos para solicitar la baja voluntaria de la entidad, estableciendo su calificación como justificada.

El carácter secreto de la votación acostumbra a preverse con carácter imperativo, de modo que los estatutos no pueden suprimirlo ni tampoco establecer requisitos o condiciones para hacerlo más gravoso (p.ej., exigiendo condiciones o requisitos no previstos en la ley para proceder a la votación secreta, etc. $)^{21}$. En términos generales, la ratio de la exigencia del voto secreto (v. infra apartado 3) determina el carácter imperativo de los supuestos en que legalmente se impone. Con todo, esta imperatividad presenta excepciones, y queremos reseñar aquí las tres que nos parecen más frecuentes.

a) En primer lugar, podemos encontrar disposiciones que condicionan la votación secreta a que los estatutos así lo establezcan (p.ej., art. 32.5.II LCCMancha, respecto a la exclusión de socios) u otras que prevén la votación secreta salvo disposición estatutaria en contrario (p.ej., art. 50.3 LCAst, en relación con la elección o revocación de los miembros de los órganos sociales o el acuerdo para ejercitar, transigir o renunciar a la acción de responsabilidad contra estos miembros).

b) En segundo término, también es posible encontrar algún caso donde se prohíbe expresamente el voto plural. Es el caso, señaladamente, de la normativa andaluza de cooperativas, donde los arts. 34.2.II LSCAnd y 33.5 Decreto 123/2014 establecen que las votaciones de las asambleas de delegados o asambleas de segundo grado «[e] $n$ todo caso [...] serán públicas». La rotundidad con que se expresan estos preceptos, unido a su carácter de norma especial, permiten concluir que prohíbe que los acuerdos de las asambleas de delegados de las cooperativas andaluzas sean adoptados mediante votación secreta. La razón de esta prohibición ha de buscarse, por un lado, en que los delegados tienen la condición de mandatarios de los socios de base (vid. art. 33.5 Decreto 123/2014) y, por tanto, tienen el deber de rendirles cuentas de su actuación en la asamblea de segundo grado (arg. art. 1720 CC ${ }^{22}$. Y, por otro lado, en el distinto número de votos que ostentará cada delegado y que hará prácticamente inviable que su votación se mantenga en secreto. Por ello, y aunque nada diga la correspondiente ley de cooperativas, parece posible afirmar, con carácter general, que el voto secreto es difícilmente conciliable con

21. El carácter imperativo de los supuestos legales de votación secreta viene reconocido unánimemente por la doctrina. Ya durante la vigencia de la anterior LGCoop 1987, PAZ CANALEJO manifestó reiteradamente esta opinión (1988:40; 1990:62-63; 1995:257-258).

22. En este sentido, el art. 33.5 Decreto 123/2014 establece expresamente que las personas delegadas «están obligadas a actuar con buena fe y la diligencia de una persona mandataria». 
las asambleas de delegados ${ }^{23}$. La prohibición del voto secreto no afecta a las juntas preparatorias o asambleas de primer grado, que se rigen en esta cuestión por las reglas generales.

c) En fin, creemos posible que, bajo ciertas circunstancias, los socios asistentes a la asamblea que tengan derecho de voto decidan, de forma unánime, prescindir de la previsión legal que exige el voto secreto y, por tanto, acuerden que la votación será pública o abierta. Con todo, dejamos la justificación de esta afirmación, así como sus condiciones, para un epígrafe posterior de este trabajo (vid. infra apartado 4.1.2) ya que su plena comprensión requiere haber expuesto lo que, a nuestro juicio, constituye la ratio de la exigencia del voto secreto.

\subsection{Votación secreta por disposición estatutaria}

El art. 25.3 LCoop permite que los estatutos sociales añadan otros supuestos de votación secreta a los específicamente contemplados por la Ley. La misma previsión contienen la mayoría de leyes autonómicas de cooperativas ${ }^{24}$. Y la misma facultad ha de atribuirse a los estatutos en aquellas otras leyes autonómicas (LSCAnd, LFCNav, LCAst, TRLCAr, TRLCCVal y LCCat) que no lo prevén expresamente, ya que otra cosa no sería congruente con el papel que los estatutos de las cooperativas desempeñan en el principio de gestión democrática de los socios ni con el derecho de minoría a solicitar que los acuerdos se adopten con voto oculto. En efecto, si la petición de una minoría de socios o de votos sociales puede activar la votación secreta, con mayor razón ha de admitirse el acuerdo mayoritario o unánime de incluir nuevos supuestos de votación secreta en los estatutos.

En torno a esta posibilidad de ampliar estatutariamente los supuestos de voto secreto, hay que hacer tres breves observaciones.

En primer lugar, los estatutos no poseen restricciones a la hora de establecer qué otros acuerdos, además de los previstos por la Ley, serán adoptados mediante voto

23. Vid. al respecto, en la doctrina italiana, PETRELLI (2005:26). La idea del texto parece encontrarse también en la SAP Córdoba (Secc. 1a) 403/2019, de 21 de mayo (ECLI:ES:APCO:2019:279), cuando, aunque sea obiter dicta, señala que "habría que preguntarse si por cuestiones de transparencia en la actuación de esos socios delegados, sea más correcta de cara a quienes han confiado en ellos, que conste lo que han votado, y a eso es posiblemente a lo que haya atendido el artículo 33.5 del Reglamento de la Ley de Sociedades Cooperativas Andaluzas".

24. Vid. arts. 39.5 LCCan, 34.4 LCCLeón, 34.2.I LCCMad, 51.5.I LCCMancha, 36.8 LCEusk, 35.5 LCGal, 41.6 LCIBal, 39.4 LCRio y 42.4 LCMur. También en Portugal, el art. 32.4 de la Lei no 119/2015, de 31 de agosto, que aprueba el Código Cooperativo, prevé que los estatutos puedan ampliar los casos en que la votación secreta será obligatoria. 
secreto. Es decir, que los estatutos podrán someter a voto oculto cualquiera de las decisiones que deba tomar la asamblea general, ya sean de su exclusiva competencia, hayan sido asumidas por ésta por no ser competencia exclusiva de otro órgano social, o bien se trate de impartir instrucciones al consejo rector o someter a autorización la adopción por este órgano de decisiones o acuerdos sobre determinados asuntos (cfr. art. 21 LCoop). En el caso más extremo, incluso podría pensarse en una cláusula estatutaria que exigiera el voto secreto en la adopción de todos los acuerdos de la asamblea general ${ }^{25}$. Esta opinión se ve fortalecida en aquellas leyes (autonómicas) que disponen expresamente que la votación secreta rogada pueda ser solicitada «sobre cualquier punto del orden del día» ${ }^{26}$.

En segundo término, no hay inconveniente en que los estatutos de la cooperativa sometan a condiciones los nuevos supuestos de voto secreto (p.ej., el acuerdo de traslado del domicilio social será adoptado con voto secreto salvo que el $20 \%$ de los votos sociales manifieste lo contrario, el acuerdo de fusión de la cooperativa será adoptado con voto oculto cuando la sociedad absorbente o resultante sea otra cooperativa de la misma clase, etc. $)^{27}$, siempre que no sean discriminatorias o atenten contra los principios cooperativos. Es evidente que quién puede lo más -establecer que en todo caso un acuerdo será adoptado con voto secreto-, puede lo menos -introducir condiciones para que este acuerdo sea adoptado mediante voto secreto-.

En fin, cabe plantearse si el reglamento de régimen interno de la cooperativa podrá ampliar los supuestos de votación secreta de acuerdos de la asamblea general. A nuestro juicio, la respuesta debe ser negativa, en base a una doble razón. La primera deriva de la propia redacción del art. 25.3 LCoop que en ningún momento alude a dicho reglamento como fuente para determinar los acuerdos que deben ser adoptados mediante votación secreta. Y la segunda razón ha de buscarse en la naturaleza del reglamento como mero instrumento de desarrollo de los estatutos que, por tanto, no

25. En este sentido, SEDA HERMOSÍN (2002:382), comentando el art. 50.5 LSCAnd 1999, señala que, aunque no lo diga el precepto, los estatutos pueden ampliar los casos de votación secreta, «e incluso imponer este criterio de votación secreta como regla general en todo caso». Sin embargo, en el caso de la normativa andaluza vigente hay, al menos, un caso en que los estatutos no podrán imponer que la votación sea secreta. Nos referimos a los acuerdos adoptados por los delegados en la asamblea de segundo grado, que se exige que «en todo caso [...] serán públicas» (art. 34.II LSCAnd y 33.5 Decreto 123/2014).

26. Así, arts. 39.5.II LCCan, 34.4 LCCLeón, 51.5.II LCCMancha, 30.3 LSCAnd, 44.8 LSCExt y 34.5TRLCAr.

27. Una cláusula de este tipo podemos encontrarla en los estatutos tipo elaborados en 2011 por la Federazione Italiana delle Banche di Credito Cooperativo e Casse Rurali (Federcasse) para los bancos de crédito cooperativo italianos, en los que se dispone que el nombramiento de cargos sociales se hará mediante voto secreto, salvo que la asamblea, a propuesta de presidente, decida con la mayoría de al menos de los dos tercios de los votos emitidos que el voto será manifiesto (art. 28.III). 
pueden sustituir a éstos en las funciones y contenido que les atribuye el legislador. Estos mismos argumentos sirven, como se verá, para negar que el reglamento de régimen interno pueda incluir cautelas para evitar abusos en la votación secreta rogada (p.ej., estableciendo que solo procede una votación secreta de este tipo para cada asamblea general) así como también para rechazar que pueda modificar las reglas legales dispositivas que regulan el sufragio secreto (p.ej., disminuyendo el porcentaje de votos necesario para exigir la votación secreta rogada). En ambos casos, se trata de normas que deberán ser incorporadas en los estatutos de la cooperativa. Sin embargo, ello no significa que el reglamento de régimen interno no pueda tener papel alguno en la configuración del voto secreto en la asamblea general de la cooperativa. El reglamento sin duda puede establecer reglas relativas a la intendencia y la logística para realizar de forma adecuada la votación secreta. Entre estas reglas pueden citarse, por ejemplo, las siguientes: uno, que el voto de los socios se depositará en una urna dispuesta al efecto en la asamblea; dos, cuál será el contenido mínimo de las papeletas y la forma de definir la pregunta que se haga a los socios (p.ej., que en la medida de lo posible la pregunta debe tener como únicas opciones posibles un «sí»o un «no» de manera que el socio solo tenga que marcar una cruz en la opción elegida); tres, que se utilizará la lista de socios que se haya elaborado en el momento de constitución de la asamblea para irlos llamando de uno en uno para que ejerzan su derecho de voto; cuatro, que el proceso de escrutinio se hará en voz alta, papeleta a papeleta; o cinco, cuál es el periodo de tiempo durante el que deben conservarse las papeletas del voto ${ }^{28}$.

\subsection{Votación secreta rogada}

\subsubsection{Legitimación para su solicitud}

El art. 25.3 LCoop dispone que la votación de la asamblea de la cooperativa será secreta en aquellos supuestos «en que asi lo aprueben, previa su votación a solicitud de cualquier socio, el diez por ciento de los votos sociales presentes y representados en la Asamblea Generali ${ }^{29}$.

28. Algunos de estos aspectos de procedimiento son mencionados en el post «El voto secreto de las Asambleas Generales», 9 diciembre 2014, que puede consultarse en la siguiente página web: www.agroalimentariasclm. coop/prensa/reportajes/599-el-voto-secreto-en-las-asambleas-generales.

29. La votación secreta rogada se prevé también en la normativa autonómica, salvo en el caso de la LFCNav, LCAst, LCCat. En estas leyes no hay duda de que los estatutos de la cooperativa podrán introducir el voto secreto a petición o por aprobación de una minoría de socios. Incluso sería posible que los estatutos obligaran a realizar votación secreta a solicitud de un solo socio, aunque una norma de este tipo es altamente improbable debido a las distorsiones que podría provocar en el funcionamiento de la asamblea general. Algo 
El primer aspecto que nos llama la atención de la norma es la distinción que realiza entre solicitud de votación secreta y aprobación de esa clase de sufragio ${ }^{30}$. Del precepto se desprende que la propuesta para que un asunto se vote de forma secreta podrá ser realizada por cualquier socio pero que solo existirá el deber de respetar esta modalidad de votación cuando respalden la propuesta el 10\% de los votos presentes o representados en la asamblea ${ }^{31}$. Este respaldo puede acompañar directamente la petición de sufragio secreto (p.ej., solicitud conjunta de este 10\%, petición por parte de un socio acompañando adhesiones que alcancen este porcentaje, etc.) o bien la solicitud del socio deberá ser sometida a consideración de la asamblea para ver si obtiene los apoyos necesarios que permitan llegar a dicho porcentaje. En este último caso, el art. 25.2 LCoop quiere que la petición sea sometida a votación en la asamblea, bastando que se manifiesten a favor del voto secreto ese $10 \%$ de votos presentes y representados, incluyendo claro está el o los que tuviera el socio solicitante. En esta votación, el voto de los socios no será en principio secreto ${ }^{32}$.

Una segunda cuestión que queremos poner de manifiesto es que, a nuestro juicio, dentro de la expresión «cualquier socio» no solo deben incluirse los socios usuarios de la cooperativa -esto es: aquellos que tienen el derecho y el deber de realizar la actividad cooperativizada ex arts. 15.2.b) y 16.2.c) LCoop-, sino también aquellos socios no usuarios que tienen derecho de asistencia y voto en la asamblea general (p.ej., socios colaboradores, socios de trabajo, etc.). Los abusos que puede ocasionar esta amplia legitimación para pedir el voto secreto deben combatirse por medio del establecimiento en los estatutos de límites a su ejercicio, tal y como permite la segunda parte del art. 25.2 LCoop, de la que nos ocuparemos después.

En tercer lugar, queremos hacer una cuádruple precisión en torno al porcentaje de apoyo que resulta necesario para que un acuerdo sea adoptado mediante voto secreto,

más prudente, aunque igual de poco probable, es que los estatutos atribuyan al presidente de la asamblea la facultad de decidir cuándo una votación debe ser secreta, como por lo demás admite un sector de la doctrina italiana [vid. por todos, sobre esta cuestión, FIMMANÓ (2002:699)].

30. Algunas normas autonómicas siguen también esta pauta (p.ej., arts. 35.5 LCGal, 39.4 LCRio o 42.4 LCMur) en tanto que otras, con mejor criterio, se limitan a exigir la solicitud por un cierto porcentaje de socios (p.ej., arts. 36.8 LCEusk o 30.3 LSCAnd) o de votos sociales (p.ej., arts. 34.4 LCCLeón o 44.8 LSCExt). Aunque, en realidad, como se ha dicho, «el resultado práctico puede que no difiera excesivamente», salvo que existan grupos de presión en la cooperativa (MORILLAS JARILLO \& MORILLAS FELIÚ, 2002:261).

31. Vid. también, GARCÍA MÁS (2001:150). El hecho de que la petición de voto secreto pueda ser efectuada por cualquier socio -aunque solo deba accederse a ella si recibe el respaldo del porcentaje de votos seńaladoha sido aplaudida por RODRÍGUEZ SÁNCHEZ (2001:257), que considera la solución legal «muy acertada y plausible» y también como «muy adecuada» al «permitir la extensión de los sistemas de votación secreta como garantía de la libertad e independencia del criterio de los socios».

32. Vid. señalando que se trata de una «votación normal o abierta», PAZ CANALEJO (1999:193). 
(pp. 169-215)

que recordemos se fija en «el diez por ciento de los votos sociales presentes y representados en la Asamblea General».

a) Como puede apreciarse, la base de cómputo viene constituida, no por los socios, sino por los votos sociales presentes y representados en la asamblea general de la cooperativa en la que se hace la petición de sufragio secreto. La distinción será relevante en aquellas cooperativas en las cuales no se sigue de manera estricta el principio democrático por existir voto plural, voto fraccionado o, en general, cualquier modalidad de voto que se aparte de la regla tradicional de que cada socio tiene un voto (cfr. art. 26 LCoop) ${ }^{33}$.

b) El legislador estatal fija en un $10 \%$ la cifra de los votos presentes y representados en la asamblea general que son necesarios para poder exigir el sufragio secreto rogado $^{34}$. Al tratarse de un derecho de minoría, ha de entenderse que este porcentaje podrá ser reducido por los estatutos de la cooperativa pero no aumentado ${ }^{35}$. Los peligros que puede comportar el uso abusivo del voto secreto como consecuencia de esta reducción deben ser combatidos, una vez más, estableciendo cautelas en los estatutos al amparo de lo previsto en el art. 25.2 LCoop. Lo que, a nuestro

33. En algunas leyes autonómicas la base de cómputo está formada por los socios y no por los votos sociales, de modo que la existencia de voto no capitario resulta irrelevante a los efectos de calcular el porcentaje necesario para aprobar la toma de acuerdos mediante voto secreto. Vid. así, arts. 36.8 LCEusk, 30.3 LSCAnd, 36.2 TRLCCVal 34.2.I LCCMad o 41.6 LCIBal, que incluye también expresamente a los asociados. En todos estos casos, o bien se prevé expresamente que el cálculo tendrá en cuenta no solo los socios presentes sino también los representados, o bien la falta de concreción del legislador (caso del art. 36.2 TRLCCVal, que se refiere a "personas socias asistentes») ha de conducir necesariamente a esta interpretación. También en el art. 18.3 del Reglamento de Cooperativas de Crédito, aprobado por el Real Decreto 84/1993, de 22 de enero, la base de cómputo de la minoría suficiente para exigir esta forma de emisión de votos viene constituida por los socios y no por los votos sociales, pero en este caso solamente por «los socios que asistan personalmente a la reunión», de forma que no se tienen en cuenta las representaciones otorgadas.

34. El 10\% es la cifra más utilizada también por las leyes autonómicas, aunque, como hemos dicho, en ocasiones se aplica sobre una base de cómputo formada por los socios y no por los votos sociales (vid. p.ej., arts. 36.8 LCEusk, 41.6 LCIBal o 30.3 LSCAnd). El porcentaje aumenta hasta el 15\% en el art. 51.5.II LCCMancha y alcanza el 20\% en los arts. 34.5 TRLCAr, 34.4 LCCLeón y 44.8 LSCExt (en los cuatro casos de los votos presentes y representados). Asimismo, merecen ser mencionados el art. 36.2 TRLCCVal que, si bien establece la cifra general del $10 \%$ de las "personas socias asistentes", también da lugar a la votación secreta siempre que lo pidan 50 de estos socios, y el art. 34.2.I LCCMad, que deja a la entera decisión de los estatutos la fijación de la minoría de socios que podrá exigir el sufragio secreto.

35. Vid. PAZ CANALEJO (1990:408) o SEDA HERMOSÍN (2002:382). En contra, señalando que los estatutos no pueden reducir el porcentaje de votos que ha de aprobar el sufragio secreto según el art. 25.3 LCoop, GARCÍA MÁS (2001:150), "por tratarse de una cuestión de carácter excepcional, y porque la Ley ya ha reducido de manera clara el requisito de la solicitud, ya que, con la nueva redacción, esta manera de pedir la votación secreta lo puede ser a instancia y solicitud de cualquier socio». 
juicio, no podrá modificarse por los estatutos es la base de cómputo integrada, como se ha dicho, por los votos presentes y representados en la asamblea general. c) El porcentaje correspondiente -legal o estatutario- se computará sobre los votos presentes y representados al inicio de la sesión, sin que se descuenten aquellos correspondientes a los socios que abandonen la reunión asamblearia antes de su finalización ${ }^{36}$. Por consiguiente, el hecho de que haya socios que se ausenten de la reunión dificultará la obtención del porcentaje necesario para exigir el voto secreto $^{37}$.

d) Puesto que la base de cálculo del porcentaje está constituido por los «votos presentes y representados", sin mayor precisión, han de computarse los emitidos por cualquiera de las personas que ejercen debidamente el derecho de voto en la asamblea general, con independencia de la clase de socio a la que pertenezcan. Por consiguiente, es posible que el $10 \%$ exigido pueda obtenerse únicamente con los votos de los socios usuarios, solo con los votos de los socios «especiales» (p.ej., socios colaboradores, socios de trabajo, etc.) o bien combinando ambos grupos de miembros ${ }^{38}$.

En cuarto término, hay que plantearse si el voto secreto puede ser solicitado respecto de cualquier acuerdo a adoptar en la asamblea general, o si en cambio existe alguna clase de decisión que necesariamente debe ser tomada con voto público. Naturalmente, quedan fuera de esta cuestión aquellos acuerdos que, por disposición legal o estatutaria expresa, deben adoptarse mediante voto oculto. En algunas leyes autonómicas esta cuestión ha sido solventada estableciendo que la votación secreta

36. Vid. así, MORILLAS JARILLO \& FELIÚ REY (2002:261). En sentido diferente, BAENA BAENA (2018:514), quien sostiene que «los votos computables han de ser los que hubiera en el momento producirse la votación y no, de ser éstos distintos, los que hubiera al constituirse la Asamblea o al formularse la solicitud de votación secreta».

37. Por otro lado, si los estatutos de la cooperativa permiten el voto a distancia y los votos emitidos de este modo se computan como presentes (vid. p.ej., arts. 46.2 LCCat, 49.9 LCCMancha o 58.4 RSCE), es evidente que se está dificultando que los socios presentes físicamente en la asamblea puedan alcanzar la minoría necesaria para exigir la adopción del acuerdo de forma secreta. La relevancia de este hecho se ha incrementado como consecuencia de la normativa especial promulgada como consecuencia de la crisis sanitaria provocada por el coronavirus que, como es conocido, ha aumentado, siquiera de forma temporal, la posibilidad de celebración de asambleas no presenciales. En este sentido, destacamos la normativa especial dictada para las cooperativas en Cataluńa, que hasta el 31 de diciembre de 2021 permite celebrar la asamblea general y adoptar acuerdos «mediante videoconferencia u otros medios de comunicación que permitan la participación a distancia de los socios y socias" (art. 9.2 del Decreto-ley 47/2020, de 24 de noviembre, emanado del Departamento de la Presidencia de la Generalitat de Catalunya).

38. En este sentido ya se pronunció, bajo la LGCoop 1987, PAZ CANALEJO (1990:408). 
podrá ser solicitada «sobre cualquier punto del orden del día»" ${ }^{39}$. Ante el silencio de la ley estatal, parece conveniente concluir que, igualmente, el voto oculto podrá ser solicitado frente a cualquier tipo de acuerdo a adoptar por la asamblea general ${ }^{40}$, con un doble límite: por un lado, aquellos casos en que la propia ley exija voto manifiesto, de forma directa o indirecta (p.ej., haciendo constar en acta la identidad de los socios que votaron a favor del acuerdo, etc. ${ }^{41}$; por otro, los acuerdos en que los estatutos exijan que el voto sea manifiesto. En este sentido, dentro de la facultad que tienen los estatutos de la cooperativa para regular el voto secreto (art. 25.2 i.f. LCoop), ha de admitirse que establezcan que ciertos acuerdos no podrán ser adoptados con esta modalidad de voto (p.ej., la fusión de la cooperativa, ciertas modificaciones de estatutos, etc.). No obstante, y como ya se dijo, esta exclusión no podrá ser acordada respecto de aquellos acuerdos que la ley establece que han de ser adoptados con voto secreto (p.ej., acuerdo que resuelva el recurso contra la expulsión de socio, acuerdo de elección de consejeros, etc.), pues esta exigencia ha de considerarse imperativa.

En quinto lugar, hay que plantearse si la votación secreta puede ser solicitada por sujetos distintos de los socios y, en particular, si puede ser impuesta directamente por el consejo rector de la cooperativa o ser solicitada por otro órgano social (p.ej., los interventores o el comité de recursos). A nuestro juicio, la respuesta debe ser negativa, en base a dos argumentos. El primero es que el voto secreto constituye una excepción en relación con el principio general de que los acuerdos se adoptan con voto manifiesto, por lo que las normas que lo establecen deben ser interpretadas de forma restrictiva. Desde esta perspectiva, el art. 25.2 LCoop, al mencionar únicamente a los socios, debe interpretarse en el sentido de que excluye la solicitud de voto secreto por parte de otros sujetos. Y el segundo argumento reside en la ratio de la exigencia del voto oculto que, como veremos infra en el epígrafe 3, es garantizar la libertad de decisión de los socios. Atendiendo a esta ratio, parece lógico sostener que solamente

39. Así, arts. 39.5.II LCCan, 34.4 LCCLeón, 51.5.II LCCMancha, 30.3 LSCAnd, 44.8 LSCExt y 34.5TRLCAr. En este caso, los estatutos no pueden restringir los tipos de acuerdo respecto de los cuales podrá solicitarse votación secreta. A estas leyes debe sumarse el art. 36.8 LCEusk que, al disponer que la votación será secreta "en todo caso» a solicitud de socios que representen el $10 \%$ de los socios presentes y representados, ha de interpretarse en el sentido de que no permite que los estatutos excluyan ciertos acuerdos de ser adoptados con esta modalidad de voto.

40. Incluidos aquellos acuerdos que se adopten válidamente sin estar incluidos en el orden del día (cfr. sobre estos acuerdos, los arts. 28.4, 35.3 y 43 LCoop). Vid. en este sentido, SEDA HERMOSÍN (2002:381-382), comentando el art. 50.5 LSCAnd 1999; y PAZ CANALEJO (1988:40; 1990:408-409), en relación con el art. 46.3 LGCoop 1987, si bien en el primero parece condicionar esta posibilidad a su reconocimiento estatutario.

41. Recordemos, una vez más, que este es el caso de los acuerdos de las asambleas de delegados de las cooperativas andaluzas, que deben ser adoptados mediante votación pública (arts. 34.II LSCAnd y 33.5 Decreto 123/2014). 
los beneficiados por la norma, esto es: los socios, deben estar legitimados para solicitar la votación secreta. Naturalmente, nada impide que la solicitud sea realizada por el miembro del consejo rector, interventor o integrante del comité de recursos que sea socio de la cooperativa, pero la petición se llevará a cabo en esta última condición y no en la cualidad de miembro de un órgano social. No obstante lo dicho, no vemos inconveniente en que los estatutos puedan ampliar la legitimación para solicitar el sufragio secreto a sujetos distintos de los socios, fijando a la vez las cautelas precisas para evitar abusos en su ejercicio ${ }^{42}$.

\subsubsection{Cautelas para impedir abusos}

El legislador estatal es consciente de los peligros que, para el funcionamiento de la asamblea general, puede comportar un mal uso del derecho a solicitar que sus acuerdos sean adoptados mediante votación secreta. Por ello, permite que los estatutos de la cooperativa introduzcan cautelas para prevenir y evitar el ejercicio abusivo de este derecho ${ }^{43}$. En concreto, el art. 25.3 LCoop establece que "[l] os Estatutos podrán regular cautelas respecto al último supuesto -esto es: la votación secreta rogada-, para evitar abusos; entre ellas la de que sólo pueda promoverse una petición de votación secreta en cada sesión asamblearia cuando, por el número de asistentes, la densidad del orden del día o por otra causa razonable, ello resulte lo más adecuado para el desarrollo de la reunión ${ }^{44}$. Esta norma nos lleva a las siguientes reflexiones.

En primer lugar, la facultad que se atribuye a los estatutos de introducir cautelas anti-abuso no permite suprimir la votación secreta rogada ni tampoco aumentar el porcentaje de votos necesario para ejercer este derecho. En ambos casos nos encontramos con normas tuitivas de la minoría, por lo que la cooperativa deberá hallar otro modo de impedir que el derecho a solicitar el voto secreto sea ejercitado de forma abusiva.

42. MORILLAS JARILLO \& FELIÚ REY (2002:261), afirman rotundamente que «ninguno de los asistentes que no ostente dicha cualidad no puede formular la solicitud».

43. Vid. advirtiéndolo, SACRISTÁN BERGIA (2007a:484), GADEA SOLER, SACRISTÁN BERGIA \& VARGAS VASSEROT (2009:242) y VARGAS VASSEROT, GADEA SOLER \& SACRISTÁN BERGIA (2015:309).

44. La norma anti-abusos también puede encontrarse en algunas de las leyes autonómicas de cooperativas. En estas pueden distinguirse básicamente dos modalidades. La primera se limita a prever la introducción estatutaria de cautelas para evitar abusos (vid. arts. 39.5.II LCCan y 34.2.I LCCMad). La segunda, siguiendo la ley estatal, añade un ejemplo de cautela que los estatutos pueden incluir para impedir tales abusos (vid. art. 51.5.II LCCMancha). No obstante, nada impide que los estatutos puedan introducir cautelas para evitar el ejercicio abusivo del derecho a pedir votación secreta también en aquellas leyes autonómicas que no lo contemplan expresamente. 
En segundo término, el art. 25.3 LCoop seńala que el establecimiento de cautelas procede «respecto al último supuesto», es decir, para el ejercicio del derecho de minoría a solicitar que los acuerdos se adopten mediante votación secreta. Esta expresión parece indicar que no es posible limitar estatutariamente el sufragio secreto en los otros dos casos previstos en aquel precepto, a saber: «en los supuestos previstos en la presente Ley o en los Estatutos». La afirmación es sin duda cierta si la referimos a los supuestos legales de voto secreto, cuya previsión ha de considerarse en términos generales imperativa. Pero no puede sostenerse en relación con los supuestos de sufragio oculto previstos estatutariamente. En este caso, parece obvio que quién puede lo más (introducir nuevos acuerdos que requieren votación secreta), puede lo menos (someter a condiciones el ejercicio del sufragio secreto en estos supuestos).

En tercer lugar, la previsión de cautelas puede resultar muy conveniente, especialmente en función del tamaño, tipología de socios y actividad de la cooperativa, pero en ningún caso aparece configurada como necesaria o imprescindible. En efecto, el uso por parte del art. 25.3 LCoop del verbo "podrán» ("los estatutos podrán regular cautelass) indica claramente que la cooperativa puede perfectamente optar por no establecer medida alguna para prevenir e impedir el ejercicio abusivo del derecho a solicitar que la votación de acuerdos sea secreta ${ }^{45}$.

En cuarto término, el art. 25.3 LCoop incluye, a modo de ejemplo, una de estas cautelas que los estatutos pueden establecer para evitar el ejercicio abusivo u obstruccionista de la votación secreta rogada. En concreto, la cautela consiste en prever que solamente podrá promoverse una única petición de votación secreta en cada sesión asamblearia. Cuatro observaciones se hacen ahora necesarias con respecto a esta norma. La primera es que se trata de un mero ejemplo, por lo que los estatutos pueden establecer otras cautelas que consideren convenientes o necesarias (p.ej., excluir la votación secreta para algunos acuerdos, requerir que la petición ha de hacerse con cierta antelación al inicio de la reunión, exigir que el socio peticionario exponga los motivos de su solicitud de sufragio secreto, etc. $)^{46}$. La segunda observación es que, debido a este carácter ejemplificativo, los estatutos pueden optar por no incluir la cautela prevista por el legislador, en cuyo caso podrá solicitarse votación secreta para uno,

45. Vid. en este sentido, SÁNCHEZ RUIZ (2001:217), MORILLAS JARILLO \& FELIÚ REY (2002:261), PANIAGUA ZURERA (2005:207) o PAZ CANALEJO (1999:193). En cambio, la redacción del art. 34.2.I LCCMad (los estatutos «incluirán cautelas») hace pensar que en este caso la fijación de cautelas es obligatoria, y así PAZ CANALEJO (1998:155), escribe que los estatutos «deberán incluin» cautelas para evitar prácticas obstruccionistas o abusivas.

46. Vid. señalando que los estatutos pueden introducir otras limitaciones distintas, GARCÍA MÁS (2001:150) o MORILLAS JARILLO \& FELIÚ REY (2002:261). 
varios o todos los asuntos que la asamblea deba votar ${ }^{47}$. En tercer lugar, la limitación de las votaciones secretas a una por asamblea persigue sustancialmente evitar que la reunión se prolongue en exceso, ya que una duración desmedida va en detrimento de la participación del socio y, por consiguiente, del principio cooperativo de gestión democrática ${ }^{48}$. En fin, una última observación es que la restricción del número de peticiones de votación secreta en una asamblea debe estar justificada (en este caso, sea "por el número de asistentes», por "la densidad el orden del día» o bien "por otra causa razonable») y resultar «lo más adecuado para el desarrollo de la reunión». Ello denota que debe encontrarse un equilibro entre las cautelas estatutarias destinadas a impedir abusos y la configuración de la petición de votación secreta como un derecho de minoría. Sin embargo, este equilibro es notablemente difícil de conseguir, máxime cuando se utilizan numerosos conceptos jurídicos indeterminados para delimitar aquellas cautelas (p.ej., "causa razonable»o "lo más adecuado») ${ }^{49}$.

Por último, advertiremos que la ausencia en los estatutos de cautelas anti-abuso no impide que la cooperativa pueda defenderse ante el ejercicio abusivo del derecho a solicitar la votación secreta por parte de los socios ya que, en cualquier caso, será de aplicación el art. 7.2 del Código Civil. No obstante, también parece claro que la cooperativa podrá combatir de forma más segura y eficaz el abuso si diseña claramente en los estatutos los límites de la votación secreta rogada que si debe recurrir a la -siempre más indeterminada- cláusula general del art. 7.2 CC. En aplicación de este precepto, hay que atribuir a la mesa de la asamblea general, aun en caso de silencio estatutario, la facultad de rechazar peticiones de votación secreta que considere abu-

47. Vid. sobre esta pluralidad de votaciones secretas en una misma asamblea, PAZ CANALEJO (1990:408409). En este caso, los estatutos pueden imponer la cautela de que la petición de votación secreta se haga al inicio de la sesión manifestando ya en este momento todos los acuerdos para los que se solicita. Precisamente, la SAP Pontevedra (Secc. 1a) 198/2002, de 22 de mayo (ECLI:ES:APPO:2002:1723) resuelve un caso en el que el Tribunal considera que, aunque la redacción del acta suscita dudas, no puede entenderse que el acuerdo sobre el voto secreto, adoptado al iniciarse la asamblea, se limitara al primer punto del orden del día.

48. Vid. PAZ CANALEJO (1999:193), señalando que si las cooperativas son cuidadosas al redactar los estatutos evitarán los peligros de que las sesiones asamblearias se prolonguen hasta altas horas de la madrugada porque una minoría de socios trata de arruinar la asamblea. De hecho, la previsión de que los estatutos pueden establecer cautelas para evitar abusos fue introducida durante la tramitación parlamentaria de la LCoop, fruto de la admisión en el Informe de la Ponencia de la enmienda no 156, presentada por el Grupo Parlamentario de Coalición Canaria, y cuya justificación era "evitar que un derecho de minoría pueda bloquear el normal desarrollo y conclusión de la Asamblea, si a lo largo de una sesión con numerosos asistentes o en horas ya tardias se ejercita varias veces la petición de votaciones secretas» (vid. Boletín Oficial de las Cortes Generales, Congreso de los Diputados, VI Legislatura, Serie A: Proyectos de Ley, 17 de noviembre de 1998, Núm. 125-7, pp. 93-94).

49. En opinión de GARCÍA MÁS (2001:150-151), la regulación de los estatutos para evitar abusos debe incluir medidas específicas y no de carácter general, "porque ello significaría poder llegar a desnaturalizar y dejar sin efectos una facultad o derecho, que la Ley concede a todos los socios". 
sivas, sin perjuicio del derecho de los solicitantes a impugnar el acuerdo discutiendo las razones que llevaron a dicha mesa a denegar su petición ${ }^{50}$.

\section{Ratio del voto secreto}

En la doctrina, existen diversas posiciones en relación con el voto secreto. Por un lado, hay quienes defienden que esta modalidad de voto debería generalizarse hasta convertirse en la mecánica habitual de adopción de acuerdos, pues las votaciones abiertas (p.ej., por el método de «aclamación» o el de «mano alzada») «crean recelos entre los cooperativistas que reducen la verdadera democracia empresarial, ${ }^{51}$. Sin embargo, una generalización del voto secreto no sería conveniente, al menos, por un doble orden de motivos. De una parte, porque su uso acostumbra a complicar la emisión y cómputo de los votos y, por tanto, a generar dificultades en el desarrollo de la asamblea (p.ej., dilatando su duración). De otra, porque parece más razonable que la cooperativa pueda decidir qué modalidades de adopción de acuerdos quiere utilizar, imponiendo la normativa solo una de ellas cuando se trate de salvaguardar ciertos intereses que requieren o justifican esta intervención legal.

En el otro extremo, podemos encontrar autores que sostienen que la imposición legal del secreto de la votación para tomar algunos acuerdos parece excesiva -especialmente en cooperativas con escaso número de socios- y que hubiera bastado con establecer que la votación debe ser secreta solamente cuando sea expresamente solicitado por alguno de los socios ${ }^{52}$. Esta opinión tampoco nos parece acertada. Los intereses que se protegen a través del voto secreto hacen conveniente que, respecto a ciertos acuerdos, deba ser respetado, con independencia del tamańo y del número de socios de la cooperativa. Y es que es precisamente en las cooperativas con menos socios donde estos riesgos son mayores y, por tanto, los socios están más necesitados de la protección que les dispensa el ejercicio secreto del voto. Lo que, como se verá (vid. infra epígrafe 4.1.2), no debe excluir la posibilidad de que, bajo ciertas circunstan-

50. Vid. MORILLAS JARILLO \& FELIÚ REY (2002:261), que parecen entender que en caso de falta de previsión estatutaria la admisión de solicitudes de voto secreto dependerá del buen criterio de la mesa. No obstante, considera esta opinión cuestionable BAENA BAENA (2017:204; 2018:514), que advierte que no queda claro qué ocurre si los estatutos no incluyen cautelas anti-abuso "pues del tenor literal de la Ley se desprende que solamente cabrá restringir las votaciones secretas en caso de previsión estatutaria, solución que maniata a la Mesa en la adecuada dirección de la sesión».

51. En este sentido, BORJABAD GONZALO (2014:199), en relación con la normativa catalana.

52. Vid. con esta opinión, ALONSO ESPINOSA (2001:244) y PASTOR SEMPERE (2006:537). 
cias, los socios asistentes a la asamblea puedan acordar de forma unánime prescindir de la protección que les brinda el voto secreto.

Para poder valorar adecuadamente estas posiciones doctrinales se hace preciso indagar la razón que lleva al legislador a imponer la votación secreta para algunos de los acuerdos adoptados en la asamblea general de la cooperativa.

La doctrina considera que el objetivo primordial de la imposición del voto secreto es permitir al socio (o a las demás personas con derecho de voto en la asamblea general de la cooperativa) ejercer con plena libertad e independencia su derecho de voto ${ }^{53}$. En otros términos, la votación secreta evita las posibles presiones derivadas del hecho de que se sepa lo que cada persona vota ${ }^{54}$. Desde esta perspectiva, es evidente que la exigencia del voto secreto está estrechamente vinculada con el principio cooperativo de gestión democrática de los socios ya que, como es fácil aceptar, sin libertad de voto no se puede alcanzar la verdadera democracia cooperativa, por mucho que exista igualdad de voto entre los socios ${ }^{55}$.

Sin embargo, ello no termina de explicar por qué el voto secreto se impone legalmente en la adopción de algunos acuerdos y no en otros, ya que parece fácil convenir que el socio debe poder votar con libertad e independencia, y al margen de presiones, en todos los acuerdos de la asamblea general de la cooperativa. Este hecho ha sido advertido por algunos autores, que aclaran que el voto secreto ha sido previsto para

53. En este sentido, VICENT CHULIÁ (1990:695), que en relación con la elección de consejeros habla del "fin de garantizar la libertad de voto»; o PAZ CANALEJO (1988:40; 1990:409), que alude, respectivamente, a la "garantía de independencia y libertad en su emisión" y a la "garantía de la libertad e independencia del criterio de los socios»; y, entre los más recientes, BAENA BAENA (2017:203; 2018:512-513), señalando que el voto secreto "quiere garantizar la libertad e independencia de criterio de los socios». También en Italia la doctrina alude a la libertad de voto como fundamento de la exigencia de la votación secreta [vid. por todos, PETRELLI (2005:20-21)].

54. Aluden a la relevancia del voto secreto para evitar que las presiones condicionen la decisión del socio, por ejemplo, LLUÍS Y NAVAS (1972:650), comentando el art. 41.1 del Reglamento de Cooperativas de 1971, que preveía el voto secreto para la elección de los administradores; ELEJABARRIETA GOIENETXE (1999:79), en relación con el art. 20.4.II LCEusk, que establece la votación secreta de la asamblea a la hora de resolver el recurso contra la decisión del consejo rector de rechazar la admisión de una persona como socio; o MACÍAS RUANO (2016:76), en referencia tanto al acuerdo de exclusión del socio como al acuerdo de elección de los miembros de los órganos sociales previstos en la ley estatal de cooperativas.

55. Vid. PAZ CANALEJO (1986/1987:25; 1995:259), quien en la primera referencia señala que la votación secreta rogada "es una técnica, en cierto modo, autentificadora y garantizadora de la calidad y conciencia democrática de las decisiones obtenidas por dicho procedimiento", en tanto que en la segunda referencia advierte que el voto secreto en el acuerdo de expulsión de socios es "garantía no sólo de democracia sincera sino también de seguridad jurídica y de legitimidad disciplinaria para todos los afectados directa o indirectamente por el recurso». Más recientemente, MACÍAS RUANO (2016:75), también ha advertido que el anonimato en el sentido del voto "puede dar mayor libertad y, por tanto, mayores cuotas de democracia y, por ende, de transparencia, que el voto público». 
(pp. 169-215)

aquellos acuerdos que versen sobre cuestiones particularmente trascendentes, conflictivas, sensibles o delicadas ${ }^{56}$.

A los efectos de verificar la ratio de la imposición del voto secreto, creemos que los acuerdos para los que se requiere esta modalidad de votación pueden dividirse en dos grupos. Por un lado, los acuerdos de elección y cese de los miembros de los órganos sociales, así como para ejercer contra ellos la acción social de responsabilidad, transigir o renunciar a su ejercicio. Por otro, los acuerdos relacionados con la adquisición y pérdida de la condición de socio de la cooperativa ${ }^{57}$.

En el primer caso, esto es: elección, cese y acción social de responsabilidad de miembros de los órganos sociales, la importancia de garantizar la libertad e independencia del voto reside en la posición de dependencia económica que los socios cooperadores suelen tener respecto a sus decisiones. Esta afirmación es especialmente cierta en el caso de los administradores, que poseen amplias facultades de gestión de la relación mutualista que los socios tienen con la cooperativa ${ }^{58}$. Y es lógico que el legislador piense que esta circunstancia influirá en el comportamiento "elector» del socio en la asamblea general, en especial cuando se trata de cooperativas de trabajo asociado (pues su actividad en la cooperativa puede ser la principal fuente de sustento del socio y de su familia) o de otras clases de cooperativas que tienen un fuerte impacto en la vida del socio (p.ej., cooperativas de crédito o cooperativas de viviendas) ${ }^{59}$.

56. Así, PAZ CANALEJO (1990:409) y RODRÍGUEZ SÁNCHEZ (2001:257), en ambos casos refiriéndose a «los sistemas de votación secreta como garantía de la libertad e independencia del criterio de los socios, sobre todo en situaciones particularmente conflictivas o, al menos, delicadas»; o SEDA HERMOSÍN (2002:382), que señala que el fundamento del voto secreto reside en «la intención del legislador de potenciar la libertad de actuación de los socios y asociados, en materias especialmente trascendentes».

57. Sin embargo, hay que tener en cuenta que, como hemos visto, estos dos grupos no agotan el elenco de supuestos en que nuestras leyes de cooperativas exigen la adopción de acuerdos mediante voto secreto.

58. El poder de los administradores comienza ya con el acuerdo de admitir o no a una persona como socio (art. 13.1 LCoop) y continúa con decisiones como la dispensa de participar en las actividades cooperativizadas por causas justificadas [art. 15.2.b) LCoop], la denegación de información que ponga en grave peligro los intereses de la cooperativa o sea abusiva u obstruccionista (art. 16.4 LCoop), la calificación y determinación de los efectos de la baja de los socios (art. 17.1 LCoop), la baja obligatoria (art. 17.5 LCoop), la imposición de sanciones, incluida la expulsión [art. 18.3.a) LCoop] o, entre otras, la decisión de cuál ha de ser el plazo para hacer efectivo el reembolso de las aportaciones de los socios que causan baja de la cooperativa, dentro del máximo de cinco años -o de un ańo si la baja es por fallecimiento del socio- legalmente previsto (art. 51.5 LCoop). Naturalmente, el poder de los administradores queda mitigado por la posibilidad de recurrir sus decisiones ante la asamblea general o, en su caso, el comité de recursos, y por la facultad de impugnar los acuerdos sociales de la cooperativa.

59. Vid. en este sentido, POMELLI (2002:703) y, sobre todo, PETRELLI (2005:21), que se refiere al strapotere delle tecnostrutture como uno de los mayores problemas de la corporate governance de la cooperativa. 
Pero pensemos también en la incidencia que pueden tener en la posición individual del socio tanto las funciones fiscalizadoras y de control de los interventores (p.ej., sobre los propios socios) ${ }^{60}$ como las facultades revisoras del comité de recursos (p.ej., de la decisión de expulsar al socio, del acuerdo de imponerle sanciones económicas o de privación de derechos, etc.). De este modo, la mencionada situación de dependencia económica del socio respecto a las decisiones de los órganos sociales corre el peligro de transformarse en un estado de "dependencia psicológica» en el acto de su elección mediante votación abierta ${ }^{61}$. En otros términos, la incidencia que las decisiones de los órganos sociales tienen en la posición individual del socio de la cooperativa corre el riesgo de influir sobre el comportamiento en la asamblea del socio a la hora de decidir sobre la elección de sus miembros. De ahí que se considere que el voto secreto cumple la misión de garantizar una prudente y sana gestión de la cooperativa, posibilitando la libre elección de los cargos sociales y, por tanto, el correcto cumplimiento del principio de gestión democrática de la cooperativa ${ }^{62}$.

Por lo que respecta al segundo caso, esto es, los acuerdos relacionados con la adquisición y pérdida de la condición de socio de la cooperativa, la razón de que el legislador exija su adopción mediante votación secreta se halla en el juego combinado de las

60. Puesto que el art. 38.1 LCoop permite que los estatutos asignen al órgano de intervención funciones de fiscalización y control que no estén expresamente encomendadas a otros órganos sociales, la doctrina entiende que pueden atribuírsele funciones controladoras sobre los socios, tanto en lo que respecta al ejercicio de sus derechos como en lo relativo al cumplimiento de sus obligaciones como cooperadores [vid. PAZ CANALEJO (1994:35)].

61. Vid. PETRELLI (2005:21), que considera que la dependencia económica del socio respecto a las decisiones de los órganos rectores de la cooperativa termina transformándose en una dependencia psicológica a la hora de votar de forma abierta sobre su elección y cese.

62. Vid. PETRELLI (2005:21-22) o Trib. Bolonia 27 noviembre 2001 (en Giur. Comm. 2002/II, p. 687). La importancia de garantizar la libertad e independencia del voto en el acuerdo de elección de los miembros de los órganos sociales se pone de manifiesto claramente en Italia desde el momento en que algunos autores solamente consideran aceptable el voto secreto cuando se trata de nombrar a dichos miembros. Vid. al respecto, las referencias que recogen BALZANO (1997:778) y GENNARI (2003:872). Esta relevancia también puede apreciarse en la normativa francesa, que solo prevé el voto secreto, previa previsión estatutaria, para el nombramiento "d'administrateurs ou gérants et de commissaires aux comptes" (art. 8 de la Loi no 47-1775 du 10 septembre 1947 portant statut de la coopération). O aún en la normativa portuguesa, en la que se exige voto secreto en las «eleições dos órgãos da cooperativa» (art. 32.4 Lei no 119/2015, de 31 de agosto, que aprueba el Código Cooperativo). Esta última norma también contempla la votación secreta en los asuntos que tengan incidencia personal respecto de los cooperadores ("assuntos de incidência pessoal dos cooperadores»). En fin, también en el ámbito internacional se pone de manifiesto la importancia de que la elección de los miembros de los órganos sociales se realice mediante voto secreto. En este ámbito cabe destacar HENRY (2013:95), que sostiene que "[l] es décisions importantes au moins devraient être prises par vote secret, a fin de limiter l'influence de certains membres, dont principalement le président de l'assemblée générale. Les élections devraient toujours avoir lieu par vote secret». 
siguientes cuatro consideraciones. En primer lugar, tales acuerdos están decisivamente vinculados con el principio de puerta abierta que, como es conocido, es uno de los pilares fundamentales de la identidad cooperativa. En segundo término, se trata en todo caso de acuerdos que resuelven recursos interpuestos contra decisiones del órgano de administración de la sociedad y, por tanto, también aquí está presente la mencionada dependencia psicológica del socio. En tercer lugar, este reexamen de los acuerdos del consejo rector se revela indispensable para una correcta aplicación de los principios de participación y democracia cooperativa ${ }^{63}$. En fin, es fácil identificar los acuerdos de admisión o rechazo de un aspirante a socio, de pérdida forzosa de la condición de socio y de las consecuencias económicas de la baja, como decisiones donde los socios pueden recibir mayores presiones, no solo del órgano de administración - del que se revisa su decisión- sino también de otros socios o grupos de socios de la cooperativa (p.ej., grupo familiar del socio expulsado, grupo de sociedades en el que se integra la sociedad no admitida como socio, modalidad de socios a que pertenece quien no está de acuerdo con la calificación de la baja efectuada por el consejo rector, etc.). Todos estos argumentos convierten los acuerdos señalados en merecedores de la especial tutela consistente en el carácter secreto de su votación.

La votación secreta tiene aún mayor justificación en aquellas cooperativas donde existen varias categorías de socios (p.ej., socios usuarios y socios colaboradores, o socios cooperadores y socios capitalistas en las cooperativas mixtas, etc.). Y la razón es que en estos casos el carácter secreto del voto tutela la cohesión de los integrantes de la sociedad, y trata de evitar el riesgo de presiones por parte de la categoría de socios dominante $e^{64}$.

\section{Incidencia del carácter secreto del voto sobre el ejercicio de (ciertos) derechos sociales}

\subsection{Impugnación de acuerdos adoptados mediante votación secreta}

\subsubsection{Legitimación para impugnar}

Italia es seguramente el país de nuestro entorno donde más se ha escrito y discutido acerca de la licitud del voto secreto en las sociedades en general y en las cooperati- 
vas en particular ${ }^{65}$. Uno de los argumentos que aducen los contrarios a esta licitud es que el uso de la votación secreta impide identificar a los socios que no votaron a favor del acuerdo y, por tanto, no permite saber quiénes están legitimados para impugnarlo ex art. 2377 del Codice Civile ${ }^{66}$.

Este problema no se produce en nuestra legislación estatal de cooperativas puesto que el art. 31.4 LCoop otorga legitimación para impugnar los acuerdos nulos a «cualquier socio» y los acuerdos anulables a "los socios asistentes a la Asamblea que hubieran hecho constar, en acta o mediante documento fehaciente entregado dentro de las 48 horas siguientes, su oposición al acuerdo, aunque la votación hubiera sido secreta» (negrita nuestra) ${ }^{67}$.

En otros términos, el sufragio secreto no afecta al derecho de impugnación de acuerdos de la cooperativa porque, por un lado, el art. 31.4 LCoop otorga legitimación a todos los socios para impugnar los acuerdos contrarios a la ley (nulos), con independencia de cuál haya sido el sentido de su voto, por lo que a estos efectos deviene irrelevante conocer si el socio demandante votó a favor del acuerdo, lo hizo en contra, se abstuvo o su voto fue en blanco o incluso nulo ${ }^{68}$.

65. Por lo que respecta a las sociedades de capital, y ante el silencio legal en torno a la forma de ejercer el derecho de voto, la cuestión fue profundamente discutida hasta la modificación del art. 2375 del Codice Civile operada por el Decreto Legislativo 17 gennaio 2003, n. 6 [vid. para una amplia relación de los autores favorables y contrarios a admitir el voto secreto, PETRELLI (2005:1-2)]. La nueva redacción de este precepto parece haber acabado con la polémica ya que, al exigir que el acta de la asamblea permita identificar a los socios que votaron a favor y en contra de los acuerdos y a los que se abstuvieron, se entiende incompatible con la votación secreta [vid. p.ej., GENNARI (2003:871), MONTAGNANI (2004:490) o PETRELLI (2005:3-4)]. Sin embargo, la controversia sigue presente en el ámbito de las cooperativas ya que el art. 2519 del Codice Civile establece que se les apliquen «in quanto compatibili» las disposiciones de la sociedad por acciones y un importante sector doctrinal considera que la adopción de acuerdos en la asamblea general de la cooperativa presenta suficientes peculiaridades que hacen que no pueda aplicarse sin más aquel art. 2375 [vid. por todos, PETRELLI (2005:8-17)].

66. Este precepto otorga legitimación para impugnar los acuerdos a los socios que reúnen un triple presupuesto: primero, tengan derecho de voto respecto al acuerdo que se impugna; segundo, estén ausentes en la asamblea, hayan expresado su disconformidad con el acuerdo o se hayan abstenido; y tercero, ostenten el 5 por ciento del capital social en las sociedades no cotizadas o el 1 por mil del capital en las sociedades cotizadas. Vid. para una panorámica sobre los problemas que comporta el voto secreto con respecto a la legitimación para impugnar el acuerdo, por todos, POMELLI (2002:707-708) y PETRELLI (2005:4-5).

67. Una norma similar puede hallarse en los arts. 42.4 LCCan, 44.5.II LCRio y 47.4 LCMur. Por su parte, en el art. 39.4 LCCLeón se exige que la oposición se haga constar en el acta de la asamblea, sin que se prevea su posible ejercicio en las 48 horas posteriores. En las demás leyes autonómicas, en las que no hay una previsión específica sobre la impugnación de acuerdos anulables adoptados mediante voto secreto, también hay que entender que quedan legitimados los socios que hubieran hecho constar su oposición al acuerdo, sea en el acta de la asamblea, sea posteriormente, si la ley correspondiente permite esta oposición diferida.

68. Vid. señalando la amplitud para impugnar un acuerdo social nulo, por todos, MORILLAS JARILLO \& FELIÚ REY (2002:279), SENENT VIDAL (2003:335) y BAENA BAENA (2006:96-97). En contra, sin 
Y, por otro lado, el socio que asista a la asamblea y quiera impugnar un acuerdo contrario a los estatutos o lesivo para el interés social (anulable) adoptado mediante sufragio secreto, deberá hacer constar su oposición a este acuerdo, ya sea en el acta de la propia asamblea, o bien entregando o remitiendo un documento fehaciente a la cooperativa dentro de las 48 horas siguientes a su celebración ${ }^{69}$. Vista la redacción legal, no parece que sea aceptable otro modo de demostrar que el socio no votó a favor del acuerdo que pretende impugnar ${ }^{70}$.

No obstante, esta solución de hacer constar expresamente la oposición al acuerdo adoptado mediante votación secreta presenta, por lo que ahora interesa, un doble inconveniente.

En primer lugar, está claro que el socio que hace constar esta oposición revela el sentido de su voto y, por tanto, desaparece la protección a la libertad e independencia de la decisión del socio que es la finalidad del sufragio secreto ${ }^{71}$. Es decir, se pone al socio en la siguiente encrucijada: o bien revela el sentido de su voto y así podrá impugnar el acuerdo, o bien mantiene oculto su voto pero ya no estará legitimado para esta impugnación ${ }^{72}$.

$\mathrm{Y}$, en segundo término, existe el riesgo -bajo pero no desdeñable- de que un socio que haya votado a favor del acuerdo se arrepienta y haga constar su oposición al mismo a los solos efectos de tener legitimación activa para impugnarlo ${ }^{73}$. En el caso

embargo, CALAZA LÓPEZ (2003:94-95), considerando que el principio de buena fe impide considerar legitimados a los socios que votaron a favor del acuerdo.

69. La primera de estas soluciones - disclosure del voto en el acta de la asamblea-también ha sido propuesta en el derecho italiano por quienes sostienen la viabilidad del voto secreto. Vid. entre otros, COSTANZA (1989:11), POMELLI (2002:706-708) y Cass. 21 novembre 1996, n. 10279 (en Le società 1997, p. 776). En España, la solución de hacer constar en acta la oposición al acuerdo adoptado mediante votación secreta ya fue defendida, durante la vigencia de la LGCoop 1987, que no contenía previsión alguna en torno a la impugnación de tales acuerdos, por PAZ CANALEJO (1990:599) o por LASSALETTA GARCÍA (1994:342).

70. En cambio, el silencio sobre la cuestión en el Derecho italiano ha llevado a la doctrina favorable al voto secreto a entender que la prueba del voto no favorable puede proporcionarse por medio distinto del acta de la asamblea: vid. por todos, PETRELLI (2005:13).

71. Este es un argumento repetido en derecho italiano por los contrarios a este sufragio, que suelen considerar inaceptable la disparidad de tratamiento entre los socios que supone que el socio que quiera impugnar deba hacer constar en acta el sentido de su voto: así, por ejemplo, BALZANO (1997:779), FIMMANÓ (2002:703) o NIUTTA (1994:873).

72. Vid. señalándolo, en Italia, ANGELIS (2000:816) y, siguiéndole, SALVATORE (2001:832-833).

73. Vid. en Italia, señalando que existe el riesgo de que el socio que haya votado a favor del acuerdo manifieste no obstante su oposición en el acta con fines meramente oportunistas o recaudatorios, por muchos, NIUTTA (1994:871), FIMMANÓ (1994:151), TASSINARI (1994:501), LEONE (1997:431), PALLOTTA 
extremo, incluso podría suceder que el número de oposiciones expresadas terminara por «destruir» la mayoría con que se adoptó el acuerdo ${ }^{74}$.

\title{
4.1.2. ¿Es válido el acuerdo adoptado sin votación secreta?
}

La SAP Jaén (Secc. 1a) 316/2000, de 16 de junio (ECLI:ES:APJ:2000:1133) considera que, pese a venir exigido legalmente, el voto secreto no es un requisito esencial del procedimiento de expulsión de los socios y, por tanto, resuelve que su incumplimiento no depara la nulidad del acuerdo de la asamblea de la cooperativa que ratifica la expulsión del socio acordada por el consejo rector. Según dicha sentencia:

\begin{abstract}
Alega también la actora, hoy apelante, que el recurso que interpuso ante la Asamblea General de la Cooperativa tenía que haberse resuelto mediante voto secreto de los socios de conformidad con lo establecido en el art. 26 de la Ley 2/95 (sic) de Sociedades Cooperativas Andaluzas y el art. 38.2 de la Ley General de Cooperativa 8/87 (sic); efectivamente consta en las actuaciones que la votación en la Asamblea no fue secreta, pero esta irregularidad no es suficiente para declarar la nulidad del acuerdo adoptado, pues para decretar ésta es necesaria que se prescinda totalmente de algún trámite esencial del procedimiento, y ha quedado probado que se siguió según los Estatutos, que no contempla el voto secreto, y además se le dio oportunidad de defensa y audiencia, y ha tenido oportunidad de recurrir los acuerdos, incluso en la jurisdicción ordinaria, es por todo lo anterior que se rechaza el recurso planteado y se confirma integramente la sentencia apelada ${ }^{75}$.
\end{abstract}

(2001:222) o PALUMMO (2001:1435). Sin embargo, considerando que este riesgo es residual o marginal, POMELLI (2002:707).

74. En efecto, imaginemos en una cooperativa de nueve socios una votación secreta ajustada en la que el acuerdo se ha adoptado con cinco votos a favor y cuatro en contra. Y supongamos que tres de los socios que votaron en contra manifiestan su oposición al acuerdo en el acta de la junta, en tanto que la cooperativa recibe después, en el plazo legal de 48 horas, las oposiciones de dos socios más. En este caso, solamente ha habido cuatro votos contrarios pero hay cinco oposiciones, lo que significa que uno de los socios que votó a favor se ha opuesto indebidamente al acuerdo. Pero lo más grave es que el número de oposiciones deja entrever que solo hubo cuatro votos favorables al acuerdo por cinco contrarios y, por tanto, que el mismo no obtuvo mayoría.

75. Hay que aclarar que ninguno de los dos preceptos citados en el párrafo reproducido, hoy derogados, permiten llegar a la conclusión de que la votación secreta es dispositiva y no imperativa. Así, el art. 26.5 de la Ley 2/1985, de 2 de mayo, de Sociedades Cooperativas Andaluzas, en lo que ahora interesa, establecía que «[1] a Asamblea General resolverá en votación secreta» el recurso contra el acuerdo de expulsión adoptado por el consejo rector. Y el art. 38.2.II de la Ley 3/1987, de 2 de abril, General de Cooperativas, disponía que este recurso ante la asamblea general «se resolverá por votación secreta». 
Probablemente, la clave para comprender este pronunciamiento es que la asamblea acordó por unanimidad ratificar la expulsión del socio que, pese a haber sido convocado, no asistió a la reunión ${ }^{76}$. Y esto nos lleva a plantearnos si es posible prescindir del sufragio secreto cuando, antes de realizar la votación, todos los asistentes a la asamblea con derecho de voto lo decidan o acuerden de forma unánime. A nuestro juicio, la respuesta a este interrogante debe ser afirmativa, sobre la base de dos argumentos. El primero se basa en que el secreto se establece en beneficio del socio de modo que resulta razonable permitirle que renuncie a él y, por tanto, que acepte que la votación sea pública. Y un segundo argumento, asociado al anterior, reside en que si el secreto garantiza el voto libre e independiente, no debe haber inconveniente en que el socio permita la votación abierta si considera que no coarta dicha libertad ni va a tener consecuencias negativas para su persona. Naturalmente, el acuerdo unánime de renuncia no precisa ser adoptado, a su vez, de forma secreta.

Sin embargo, debemos ser conscientes que aceptar la renuncia por parte del socio a la votación secreta puede ser perturbador, desde una doble perspectiva. De una parte, quienes manifiestan esa renuncia, aparentemente con plena libertad, en realidad pueden haberlo hecho a consecuencia de las presiones que han recibido. De otra, el hecho de que un grupo numeroso o cualificado de socios manifiesten que están dispuestos a renunciar al voto secreto puede convertirse en una forma de presión para que los demás socios o votantes también acepten la votación pública.

Con todo, nos parece que estas eventuales perturbaciones no bastan para negar la posibilidad general de un acuerdo unánime de renuncia al voto secreto, particularmente cuando nos encontramos en cooperativas de pocos socios y que no presenten conflictos. Ahora bien, con el fin de neutralizarlas, cabe sostener, por un lado, que la renuncia del voto secreto solo podrá realizarse en los instantes previos a la adopción del acuerdo que lo requiera, ya que la valoración de si podrá ejercerse libremente el voto requiere inmediatez. Y, por otro lado, creemos que será posible impugnar el acuerdo si se puede acreditar que las presiones han provocado un vicio en el consentimiento en la emisión del voto del socio (p.ej., si alcanzaran el grado de intimidación, etc.).

A falta de dicho consentimiento unánime de los socios, la adopción del acuerdo mediante votación secreta, cuando viene impuesto legalmente, por los estatutos o a solicitud de la minoría, es un requisito imperativo, de suerte que su incumplimiento determina la nulidad de dicho acuerdo. En este caso, los intereses protegidos me-

76. En contra de la posibilidad que el acuerdo unánime soslaye el voto secreto, parece pronunciarse PAZ CANALEJO (1990:62-63; 1995:257-258), al sostener que debe mantenerse esta modalidad de voto aunque existan indicios sólidos de que el acuerdo asambleario va a ser unánime. 
diante el sufragio secreto -y que han sido expuestos supra apartado 3- lo convierten en un trámite esencial del procedimiento que ha de ser necesariamente respetado ${ }^{77}$. Aclarado lo anterior, también hay que señalar que el acuerdo adoptado sin respetar la votación secreta puede ser nulo o anulable, en función de si este sufragio viene impuesto directamente por la ley (p.ej., nombramiento de los consejeros, expulsión de socio, etc.) o si son los estatutos los que exigen que el acuerdo se adopte mediante voto secreto.

Y, por lo que respecta a la votación secreta rogada, su falta de respeto también podrá dar lugar a un acuerdo nulo, por infracción de ley (p.ej., si no se accede a la votación secreta pese a solicitarlo el 10\% de los votos legitimados), o bien a un acuerdo anulable, por vulneración de los estatutos (p.ej., si no se ha respetado alguna cautela prevista en esta norma convencional para evitar abusos en el ejercicio del derecho).

\subsubsection{Efectos de la revelación (individual) del voto secreto}

En relación con la eventual impugnación de los acuerdos sociales, y asociado a lo anterior, también debemos abordar si el socio o el votante tienen el derecho y/o el deber de mantener el secreto del voto que se ha emitido.

77. La nulidad del acuerdo que no respete la votación secreta prevista legalmente ya fue defendida por VICENT CHULIÁ (1979:544), durante la vigencia del Reglamento de la Ley de Cooperativas de 1971, que al hilo de lo dispuesto en su art. 57-Dos, afirmaba que «[p]odrá pensarse que el requisito de votación secreta es una garantía de independencia a la que cada socio o asociado puede renunciar individualmente, sin que ello afecte a la validez de la elección. No obstante, teniendo en cuenta los peligros del caciquismo y otras formas de presión que siempre harian sospechar sobre la "ibertad" con que un socio o asociado (y, por extensión, todos ellos) manifestaba su voto, es necesario interpretar esta norma con absoluto carácter imperativo, de modo que su incumplimiento directo o indirecto acarreará la nulidad del acuerdo social por contrario a la ley». Más recientemente, ya con el texto legal vigente, MORILLAS JARILLO \& FELIÚ REY (2002:260), sostienen que los supuestos de votación secreta establecidos legalmente no pueden ser suprimidos estatutariamente y, además, «la propia LC no admite excepción alguna a la regla de la votación secreta. Ello supone que los acuerdos adoptados sin votación secreta, en los casos previstos legalmente o en los estatutos, podrán ser impugnados por contrarios a éstos, según el tenor literal del art. 31 LC»; y considera acertada esta opinión, BAENA BAENA (2017:203; 2018:513). En fin, puede traerse a colación la STS 17 diciembre 1982 (RJ 198217697), que anula la asamblea en la que no se respetó el voto secreto y, además, parece considerar que, a efectos de impugnación de los acuerdos sociales, esta infracción supone considerar que el socio fue privado ilegítimamente del derecho de voto. En este sentido, y ante la alegación de que los socios demandantes no habían hecho constar en acta su oposición a los acuerdos impugnados, la sentencia recuerda que la Audiencia basa la legitimación de los actores en que han sido ilegítimamente privados de emitir su voto ya que «si como acertadamente sienta la resolución recurrida, en la Asamblea General [...] no se ejercitó el derecho al voto, al no permitirse la forma de sufragio secreto [...], es obvio que los actores asistentes a dicha Asamblea habrán de reputarse legitimados para la impugnación de los acuerdos en ella adoptados". 
(pp. 169-215)

En primer lugar, creemos que estos sujetos tienen indudablemente el derecho a mantener el secreto del voto, salvo que tengan un deber legal o contractual de revelarlo. En el ámbito cooperativo, el supuesto más relevante de deber legal de revelación del voto recae sobre los delegados de las asambleas bifásicas, que deben rendir cuentas de su actuación frente a los socios que los designaron ${ }^{78}$. Por su parte, dos son los casos en los que más habitualmente surge un deber de revelación contractual. Por un lado, aquellos de representación, en los que el socio representado puede exigir de su representante cuál fue el sentido de su voto ${ }^{79}$. Por otro, la existencia de pactos de sindicación del voto, en el que cada uno de los votantes sindicados habrá de rendir cuentas del ejercicio del derecho frente a los demás miembros del sindicato ${ }^{80}$.

En segundo término, hay que preguntarse también si el socio o el votante tienen el deber de mantener este secreto o bien si son libres de revelar el contenido de su voto. Creemos que para responder a esta cuestión hay que distinguir dos situaciones.

Por un lado, resulta claro que el deber de mantener en secreto el sentido del voto no existe cuando el socio o el votante han de revelar el sentido de su voto para poder ejercer un derecho cuyo ejercicio está condicionado precisamente al conocimiento de cuál ha sido el sentido del voto. Es el caso, señaladamente, del derecho de impugnación de los acuerdos sociales anulables y, como veremos después (vid. infra apartado 4.3), también del derecho de baja justificada, pues en ambos casos solo están legitimados para el ejercicio del derecho los socios que no votaron a favor del acuerdo.

78. Esta rendición de cuentas se torna especialmente relevante en caso de que el mandato de los delegados sea plurianual y, por ello, el art. 30.1.II LCoop exige que en este caso los estatutos regulen «un sistema de reuniones informativas, previas y posteriores a la Asamblea, de aquéllos con los socios adscritos a la junta correspondiente». Cuestión distinta es que en los casos de las asambleas de delegados el voto secreto sea difícilmente conciliable con el distinto número de votos que ostentará cada delegado. Vid. al respecto, PETRELLI (2005:26). Quizá por todo ello el legislador andaluz exige que las votaciones de las personas delegadas en la asamblea de segundo grado sean públicas (art. 34.II LSCAnd y 33.5 Decreto 123/2014).

79. Cabe tener en cuenta que en la cooperativa esta situación es mucho menos frecuente que en otros tipos sociales debido a las restricciones que se establecen a la asistencia y voto en la asamblea general por medio de representante (cfr. p.ej., art. 27.1 LCoop).

80. Vid. sobre la admisibilidad de los sindicatos o de los pactos parasociales relativos al voto en las cooperativas, PEINADO GRACIA (2013:177), VARGAS VASSEROT, GADEA SOLER \& SACRISTÁN BERGIA (2015:307-309) y, en particular, SANTOS DOMINGUEZ (2014:790-793). Con todo, como señala este último autor, en caso de voto secreto, "el incumplimiento por un sindicado del contrato de voto es casi de imposible prueba» añadiendo que, no obstante, "este riesgo de que no se emita el voto conforme a lo convenido no es justificación para la supresión del voto secreto porque el contrato de sindicación no es oponible frente a la sociedad (arg. ex art. 29 LSC), de manera que, no estando la sociedad cooperativa obligada por él, debe cumplir con las normas sobre voto secreto». Lo que sí es probable es que aquella dificultad de prueba desincentive la celebración de tales pactos de sindicación del voto: vid. en este sentido, POMELLI (2002:713). 
Por otro lado, creemos que tampoco existe un deber de mantener en secreto el sentido del voto en los demás acuerdos, salvo que los estatutos dispongan lo contrario. Es decir, que la regla general es que el socio puede renunciar individualmente al derecho a mantener en secreto su voto y, en consecuencia, revelar su contenido -en el momento de la votación, durante el escrutinio o con posterioridad- ${ }^{81}$. Para avalar esta opinión pueden utilizarse, mutatis mutandi, los mismos argumentos que en el epígrafe anterior permitían aceptar la renuncia a la adopción del acuerdo mediante votación secreta. Es resumen, el socio, como beneficiario de la previsión de sufragio secreto, puede optar por revelar el sentido de su voto si entiende que esta difusión no le reportará consecuencias negativas. No obstante, también aquí hay que tener en cuenta las posibles presiones directas e indirectas que llevan a esa revelación o derivadas de ella ${ }^{82}$.

Sin embargo, en este caso tales riesgos no parecen motivo suficiente para denegar el derecho del socio a revelar su voto cuando pueden combatirse fácilmente incluyendo en los estatutos de la cooperativa una cláusula que imponga al socio el deber de secreto del voto y establezca sanciones ante su incumplimiento ${ }^{83}$. A este respecto, dos observaciones parecen necesarias. La primera es que esta cláusula no podrá alcanzar a los casos, ya señalados, en que la revelación del voto sea necesaria para el ejercicio de un derecho, como la baja justificada de la cooperativa o la impugnación de sus acuerdos sociales. Y la segunda observación es que el incumplimiento del deber de silencio a que está sujeto el socio puede traducirse en sanciones individuales pero no ha de conllevar la nulidad del acuerdo social que se adoptó mediante votación secreta. $\mathrm{Y}$ es que mantener que la infracción del deber de secreto invalida la votación tendría el efecto perverso de permitir que la conducta de un solo socio determinara la nulidad del acuerdo social.

81. En Italia, aboga por el carácter renunciable del voto secreto, ANGELIS (2000:817), que afirma que "[l]'espressione del voto segreto resti una facoltà, suscettibile quindi di poter essere rinunziata, e non diventi un obbligo inderogabile».

82. El riesgo es advertido por VICENT CHULIÁ (1990:695), quien, con relación al voto secreto en la elección de consejeros, señala que "[p]ensemos que optan por esta actitud [de revelar el voto] un grupo numeroso y cualificado de la Cooperativa; en tal caso, se suscitará una conducta similar de los partidarios de otros candidatos, intentando arrastrar a los votantes posteriores». Por ello, este autor sostiene que el secreto del voto "debe alcanzar a todo el proceso de elección: depósito del voto sin figurar en la papeleta el nombre del votante; deber de silencio de éste sobre las personas votadas».

83. El propio VICENT CHULIÁ (1990:695), aun partiendo del deber de silencio del socio sobre el sentido de su voto, advierte que "[l] os Estatutos sociales deberían desarrollar y precisar estos puntos». En concreto, el ámbito de actuación de los estatutos será normalmente doble. Por un lado, definir qué debe entenderse por revelación indebida del contenido del voto (p.ej., disponiendo que no constituye infracción la mera manifestación verbal del socio si no viene corroborada por algún otro hecho como mostrar la papeleta de voto en público o pedir su constancia en acta). Por otro, establecer sanciones ante la infracción del deber de mantener en silencio el contenido del voto (p.ej., multa, suspensión de derechos, etc.). 


\subsection{Carácter secreto del sufragio y voto plural}

Es común afirmar que en las sociedades cooperativas el ejercicio del voto secreto se ve facilitado por la regla general y tradicional de que en la asamblea general cada socio tiene un voto (cfr. art. $26.1 \mathrm{LCoop})^{84}$. Y es que, como es fácil advertir, el hecho de que los socios dispongan de un número de votos distinto (p.ej., por ser proporcionales al capital social) genera no solo problemas de tipo técnico-organizativo, sino que puede revelar de modo indirecto cuál es el voto de ciertos socios, y también posibilita mecánicas de voto cuya admisión es discutida (p.ej., el voto divergente) ${ }^{85}$.

Sin embargo, es de sobras conocido que la regla del voto capitario presenta hoy en día diversas excepciones. Así, por ejemplo, en el ámbito de la ley de cooperativas estatal se establece que esta regla puede romperse en atención a la clase o grado de la cooperativa y a la tipología de socios que la integren (art. 26 LCoop). Algo similar sucede en las diferentes leyes autonómicas de cooperativas ${ }^{86}$.

En Italia, un sector doctrinal considera que la existencia de voto plural obstaculiza la adopción de acuerdos en la asamblea general mediante sufragio secreto. Por un lado, porque la atribución a cada socio de una única papeleta que represente el número de votos que posee resulta contradictorio con la exigencia de secreto ${ }^{87}$. Por otro, ya que la opción alternativa de entregar al socio tantas papeletas como votos ostenta, al margen de la dificultad y el coste que representa ${ }^{88}$, hace posible el voto divergente, cuya admisibilidad resulta fuertemente controvertida ${ }^{89}$.

En nuestra opinión, es cierto que el voto plural dificulta el sufragio secreto, y que esta dificultad se incrementa cuanto más compleja es la distribución del voto en la asamblea general de la cooperativa (p.ej., voto plural a socios usuarios en función de la actividad cooperativizada combinado con voto plural en función de la presencia de socios colaboradores), pero también es verdad que los problemas que se plantean

84. Vid. p.ej., en Italia, la sentencia de la Corte de Cassazione de 21 de noviembre de 1996, n. 10279; y, en doctrina, por todos, SCORDINO (1970:262), TASSINARI (1994:498) o SALVATORE (2001:834).

85. Vid. así, por todos, BALZANO (1997:777).

86. Un panorama sustancialmente actualizado del voto plural en las leyes autonómicas de cooperativas puede verse en SANTOS DOMÍNGUEZ (2014:763-767) y en VARGAS VASSEROT, GADEA SOLER \& SACRISTÁN BERGIA (2015:216-217).

87. Vid. señalándolo, por todos, PETRELLI (2005:6-7 y 15).

88. Vid. TASSINARI (1994:498) o Trib. Milano 10 marzo 1970 (Foro pad. 1971/I, c. 434).

89. Vid. con este argumento, referido principalmente a las sociedades de capital, CITROLO (1980:1025), LUMBAU (1990:837) o FIMMANÓ (2002:153) y, extendiéndolo a las cooperativas, BALZANO (1997:777778) o PETRELLI (2005:15). 
son mayormente de tipo técnico-organizativo ${ }^{90}$ de modo que no puede afirmarse que la mera existencia de voto no capitario impida el uso del voto secreto en aquella asamblea. Veamos esta afirmación con un poco más de detalle.

Ante todo, hay que señalar que ninguna de nuestras leyes de cooperativas, estatal ni autonómica, excluye de forma expresa la votación secreta en el caso de que la sociedad haya previsto voto plural en sus estatutos. De este modo, parece que, al menos en principio, todos aquellos legisladores consideran compatible el sufragio secreto en la asamblea general con la existencia de voto plural.

Aclarado lo anterior, diremos en primer lugar que en caso de voto plural no hay que descartar completamente que se atribuya a cada socio una sola papeleta que represente el número de votos que posee. Ello dependerá de si esta opción permite o no mantener de forma razonable el secreto en el voto. Así, por ejemplo, en una cooperativa de amplia base social (p.ej., 200 socios), donde son muchos los socios que poseen la misma cantidad de votos plurales (p.ej., hay 100 socios con un voto, 50 con dos votos y otros 50 con tres votos), creemos que la entrega a cada uno de una única papeleta no pone en riesgo el carácter secreto del voto expresado por cada socio ${ }^{91}$.

En segundo término, es evidente que, tal y como sostiene parte de la doctrina italiana, entregar al socio tantas papeletas como votos ostente supondrá de ordinario un aumento de las dificultades y del coste de la celebración de la asamblea general de la cooperativa. Sin embargo, también parece claro que la dificultad y el coste difícilmente serán tan elevados como para impedir que las votaciones sean secretas, si bien son dos parámetros que habrán de valorarse a la hora de diseńar estatutariamente, dentro de los límites legales, tanto el voto plural como el régimen del sufragio secreto.

En fin, otro obstáculo que plantea el sufragio secreto en caso de voto plural es que permite el voto divergente, esto es, que un mismo socio pueda votar a la vez a favor y en contra de un mismo acuerdo. Sin embargo, esta objeción tampoco sirve para rechazar per se la votación secreta a la vista de los siguientes cuatro argumentos. El primero es que el ejercicio del derecho de voto de forma divergente se admite ex-

90. Vid. señalando la existencia de estos problemas, BALZANO (1997:777).

91. Cuando el voto es proporcional al capital social o al número de socios de las cooperativas asociadas, otra opción sería hallar el máximo común divisor, con el fin de elaborar papeletas de voto que representen esta cifra para entregarlas en su debida proporción a los distintos socios en función de la cifra de capital que ostenten o del número de socios que componga su base social. Vid. al respecto, TASSINARI (1994:498). Así, por ejemplo, supongamos una cooperativa de segundo grado donde el voto se ejercita en proporción al número de socios de las cooperativas socios, que son cinco. La cooperativa A tiene 80 socios; la B, 128; la C: 48; la D: 20; y la E: 72. A la vista de estos datos, el máximo común divisor es 4, por lo que podrían entregarse a cada cooperativa papeletas que incorporaran 4 votos a razón de los números siguientes: cooperativa A: 20 papeletas; B: 32; C: 12; D: 5; y E: 18. 
(pp. 169-215)

presamente en las sociedades cotizadas (art. 524.1 LC) ${ }^{92}$ y su legitimidad tampoco parece ya discutirse en el caso de las sociedades de capital no cotizadas ${ }^{93}$. El segundo argumento es que, ante el silencio del legislador cooperativo acerca de si el voto divergente es o no posible en este tipo social, en la doctrina existen algunas voces que lo aceptan ${ }^{94}$ y que, incluso, lo consideran un instrumento idóneo para que los socios personas jurídicas puedan expresar las posiciones mayoritaria y minoritaria que pueda haber en su seno con relación a los acuerdos de la cooperativa ${ }^{95}$. En tercer lugar, y con independencia de estas posturas doctrinales, el voto divergente se muestra imprescindible en el caso de asambleas bifásicas en las que los delegados tengan un mandato imperativo de los socios ${ }^{96}$. Por último, el riesgo de voto divergente, aunque no pueda estimarse inexistente, sí puede calificarse como escaso o residual, tanto por los socios a los que afectará (p.ej., aquellos que quieran expresar la pluralidad de opiniones que pueda haber en su seno, como son las personas jurídicas) como por el número de veces que se producirá (p.ej., es probable que solo en ciertas cooperativas y únicamente ante determinados acuerdos que afecten especialmente al socio votante $)^{97}$.

92. Según este precepto, «[1] as entidades que aparezcan legitimadas como accionistas en virtud del registro contable de las acciones pero que actúen por cuenta de diversas personas, podrán en todo caso fraccionar el voto y ejercitarlo en sentido divergente en cumplimiento de instrucciones de voto diferentes, si asi las hubieran recibido».

93. Vid. por todos, MENÉNDEZ MENÉNDEZ (2007:955-968), SÁNCHEZ-CALERO GUILARTE (2015:2143-2178) y, últimamente, ALFARO ÁGUILA-REAL (2018), en su blog Almacén de Derecho.

94. Siquiera sea con carácter limitado: vid. p.ej., ALFONSO SÁNCHEZ (2002a:524-527; 2002b:148-151), que lo admite con fuertes cautelas y salvedades; o SENENT VIDAL (2003:397-398), que parece admitirlo cuando valora si el socio que votó de forma divergente está legitimado para impugnar los acuerdos anulables. En contra, rechazando el voto divergente sin matices, BORJABAD GONZALO (1993:92), SANTOS DOMÍNGUEZ (2014:775) y, con la salvedad de los delegados que ostenten mandato imperativo, VICENT CHULIÁ (1978:457-458).

95. Vid. así, PAZ CANALEJO (1990:439-440, 444-445).

96. El art. 30.1 LCoop establece que los estatutos establezcan «el carácter y duración del mandato» de los delegados. En términos generales, este mandato puede ser facultativo, indicativo o imperativo. En el mandato facultativo los socios confían en el criterio que el delegado adopte ante los acuerdos de la asamblea, lo que permite que el delegado vote en una sola dirección. En el mandato indicativo al delegado se le imponen solo unos criterios o instrucciones (generales) dentro de los cuáles ejercitará él mismo la elección, sin que pueda transgredirlos aunque exista divergencia con otros mandatos que ostente. Y en el mandato imperativo el delegado es un mero portavoz del voto del socio, por lo que el voto divergente resulta necesario para que pueda manifestar las distintas posiciones de los socios mandantes. Vid. señalando el ejercicio de voto divergente por parte del delegado con mandato imperativo, VICENT CHULIÁ (1978:457-458) o GONZÁLEZ TAUSZ (1998:1473).

97. Vid. en este sentido, en Italia, POMELLI (2002:708-709). 
En cualquier caso, hay que tener en cuenta que el art. 26.7 LCoop dispone que «los socios titulares de votos plurales podrán renunciar para una Asamblea o en cualquier votación, a ellos, ejercitando un solo voto», y que "[a]demás, los Estatutos deberán regular los supuestos en que será imperativo el voto igualitario». En especial, y a tenor de esta última regla, la cooperativa puede evitar que se aplique voto plural en la adopción de acuerdos mediante votación secreta si, de acuerdo con el art. 26.7 LCoop, establece en los estatutos que el voto igualitario será imperativo para la adopción de dichos acuerdos. En esta hipótesis, hay que tener en cuenta que, cuando la cláusula estatutaria comprenda la votación secreta rogada entre los supuestos de exclusión del voto plural, será particularmente importante definir las cautelas anti-abuso ex art. 25.3 LCoop para evitar que la minoría pueda, de facto, desactivar el voto plural mediante la solicitud reiterada de sufragio secreto.

\subsection{Acuerdos que dan lugar al derecho a causar baja justificada de la sociedad}

Como es sabido, la adopción de ciertos acuerdos por la cooperativa otorga al socio disconforme el derecho a darse de baja de forma justificada. En la mayoría de estos casos el carácter justificado de la baja se condiciona a que el socio no vote a favor del acuerdo o esté disconforme con el mismo.

En este sentido, se ha advertido que la adopción de alguno de estos acuerdos mediante votación secreta impide el ejercicio del derecho de baja justificada por cuanto, al desconocerse el sentido del voto de cada socio, no se sabrá quiénes son los disconformes ${ }^{98}$.

Sin rechazar la dificultad de hacer compatible el voto secreto con el ejercicio del derecho de baja justificada, creemos que un examen más detallado de esta relación requiere efectuar tres breves consideraciones.

En primer lugar, ninguno de los acuerdos que legalmente deben adoptarse con voto secreto genera el derecho de baja justificada a favor del socio disconforme. Es cierto que los estatutos pueden ampliar el elenco de causas de baja justificada incluyendo alguno o todos aquellos acuerdos, pero en este caso lo lógico sería que aclararan de qué modo ha de exteriorizarse la disconformidad del socio que le legitima para ejercer el derecho de separación.

En segundo término, podría suceder que los estatutos ampliaran los casos en que la votación debe ser secreta para incluir a algunos o todos los acuerdos que generan el derecho del socio a causar baja justificada de la cooperativa. También en este caso

98. Este problema ha sido particularmente puesta de manifiesto en el derecho italiano: vid. por todos, NIUTTA (1994:871). 
(pp. 169-215)

debe pensarse que, como parte de las cautelas para evitar abusos (art. 25.3.II LCoop), los estatutos fijarán cómo debe acreditarse la disconformidad del socio con el acuerdo adoptado con voto secreto que da lugar al derecho de baja ${ }^{99}$.

En tercer lugar, debe abordarse el caso en que, por no haber fijado los estatutos dichas cautelas o por tratarse de votación secreta rogada, no dispongamos de previsiones específicas sobre cómo hacer compatible el voto secreto con la identificación de los legitimados para ejercitar el derecho de baja justificada. En esta hipótesis hay que distinguir dos situaciones distintas.

Por un lado, es claro que ninguna dificultad existe para afirmar la legitimación de los socios que no asistieron a la junta, pues esta circunstancia resultará de la relación de asistentes que necesariamente debe incluirse en el acta de la asamblea (art. 29.1 LCoop $)^{100}$. Por otro lado, si el socio ha asistido a la asamblea, y de forma similar a lo que sucede en el caso de impugnación de acuerdos anulables adoptados mediante sufragio secreto, cabe sostener que poseerá derecho a causar baja justificada cuando haga constar en el acta de la asamblea que su voto no fue favorable al acuerdo ${ }^{101}$. Por

99. Una de las opciones, por ejemplo, sería traer aquí lo previsto para el caso de impugnación de acuerdos sociales adoptados mediante votación secreta (art. 31.4 LCoop) y legitimar para el ejercicio del derecho de baja justificada al socio que hubiera expresado su oposición al acuerdo en el acta de la asamblea o mediante documento fehaciente entregado a la sociedad dentro de las 48 horas siguientes. Otra posibilidad es diseñar un sistema de voto «relativamente» secreto en el que el sentido del voto de los socios solamente sea conocido por escrutadores independientes a los que se imponga el deber de mantenerlo en secreto y a quienes pueda acudirse cuando exista la necesidad de probar que un socio no votó a favor del acuerdo y que, por tanto, está legitimado para ejercer el derecho de separación (p.ej., mostrando la papeleta de voto del socio que dichos escrutadores tiene la responsabilidad de conservar). Vid. sobre esta posibilidad, ya defendida con anterioridad en el derecho inglés, POMELLI (2002:714).

100. Otros casos serán igualmente sencillos: p.ej., la inexistencia de socios con derecho de separación en el caso de que el acuerdo se haya adoptado por unanimidad de todos ellos, circunstancia que también debe desprenderse sin dificultad del acta de la asamblea puesto que en la misma debe constar «la transcripción de los acuerdos adoptados con los resultados de las votaciones» (art. 29.1 LCoop).

101. Esta es la solución que un sector doctrinal defiende en el derecho italiano con respecto al diritto di recesso: vid. p.ej. ASQUINI (1970:499), MASCHIO (1972:982) o COSTANZA (1989:11) así como, en jurisprudencia, Cass. 21 novembre 1996, n. 10279 (en Le società 1997, p. 776). Sin embargo, los términos en que se plantea la cuestión en Italia son, al menos, parcialmente distintos a los de nuestro país por cuanto el art. 2437.III Codice Civile establece de forma expresa la nulidad de los pactos que hagan más gravoso el ejercicio del derecho de separación, entre los que buena parte de la doctrina incluye la exigencia de que el socio tenga que hacer constar en el acta de la asamblea su disconformidad con el acuerdo: vid. p.ej., NIUTTA (1994:871-872), FIMMANÓ (2002:704) o PETRELLI (2005:14). Además, queremos exponer otras dos ideas. La primera es que, ante el silencio legal o estatutario, la constancia del sentido del voto en el acta no puede considerarse el único modo para acreditar la disconformidad del socio con el acuerdo, de modo que poseerá legitimación para la baja justificada el socio que demuestre por otros medios que no ha votado a favor del acuerdo (p.ej., consta que ha abandonado la reunión antes de la votación del acuerdo, o que ha sido privado del derecho de voto, etc.). Y la segunda idea es que, a falta de norma que lo establezca, resulta difícil extender 
tanto, aquí también el socio debe elegir: o mantiene el carácter secreto del voto y pierde la justificación de la baja, o exterioriza el sentido de su voto, en cuyo caso cesa para este socio la protección que le dispensa el sufragio secreto ${ }^{102}$.

\subsection{Deber de abstención del socio en conflicto de intereses y voto secreto}

El art. 26.8 LCoop dispone que los estatutos «establecerán los supuestos en que el socio deba abstenerse de votar por encontrarse en conflicto de intereses, incluyendo en todo caso aquéllos previstos en la Ley de Sociedades de Responsabilidad Limitada». Entre los problemas que ocasiona este precepto, están los que la votación secreta genera en aquellos acuerdos donde uno o varios socios de la cooperativa se encuentran en situación de conflicto de intereses. En este ámbito, conviene distinguir, por un lado, el deber de abstención del socio en la votación y, por otro, la circunstancia de que el socio haya emitido el voto infringiendo este deber.

En primer lugar, el carácter secreto del voto no debe impedir la identificación de la situación de conflicto de interés antes de que se produzca la votación y, una vez advertida esta situación, tampoco debe ser un obstáculo para negar ex art. 26.8 LCoop el ejercicio del voto del socio incurso en este conflicto ${ }^{103}$. Estas son actuaciones previas a la emisión del voto y, por tanto, no quedan afectadas por la modalidad de su ejercicio y, en particular, por el hecho de que sea secreto.

Distinto es el caso en que, pese a incurrir en conflicto de interés, el socio infrinja su deber de abstención y emita el voto de forma secreta. Estas emisiones indebidas del voto se resuelven con la denominada "prueba (o test) de resistencia», lo que significa que el acuerdo solamente será anulado si el voto del socio que infringió el deber

al derecho de separación la previsión del derecho de impugnación que también permite ejercitar la acción de anulabilidad del acuerdo a quienes hayan remitido su oposición a la sociedad en las 48 horas siguientes a la celebración de la asamblea general.

102. En la normativa autonómica, solo el art. 97.3 LCCMancha contempla la votación secreta en el seno de un acuerdo que otorgue derecho de baja justificada del socio disconforme. Según este precepto, si la modificación de estatutos sociales consiste en el cambio de clase de la cooperativa, tienen derecho a separarse de la sociedad, "aunque la votación hubiera sido secreta», los socios que hubiesen hecho constar, en acta o mediante documento fehaciente entregado dentro de las 72 horas siguientes, su oposición al acuerdo, así como también los socios ausentes y los que hayan sido ilegítimamente privados de emitir su voto.

103. En cuanto a la identificación de la situación de conflicto de interés, parece que caben dos situaciones. De una parte, que sea el propio socio quién advierta de la existencia del conflicto. De otra, que el conflicto sea puesto de manifiesto por otro sujeto (p.ej., otro socio), en cuyo caso corresponde al presidente de la asamblea verificar y declarar esa existencia. En cualquier caso, corresponde a dicho presidente impedir la votación del socio en conflicto de intereses, sin perjuicio de la facultad de impugnar esta decisión cuando se considere que ha sido errónea. 
de abstención resulta determinante para obtener la mayoría requerida ${ }^{104}$. Sin embargo, es fácil convenir que la aplicación de la "prueba de resistencia» requiere conocer el sentido del voto del socio infractor, lo que no sucede cuando la votación es secreta. A la vista de esta circunstancia, podría concluirse, como ha hecho parte de la doctrina italiana, que los acuerdos en los que exista un conflicto de intereses de alguno de los socios no pueden adoptarse mediante votación secreta ${ }^{105}$. No obstante, este obstáculo para el voto secreto será probablemente de escasa relevancia si tenemos en cuenta las siguientes tres observaciones.

En primer lugar, como serán los estatutos los que recojan los casos de conflicto de interés (art. 26.8 LCoop), ha de entenderse que también incorporarán las cautelas precisas para hacerlos compatibles con una votación secreta (p.ej., previendo qué sucederá si la situación de conflicto no se conoce hasta unos días después de la votación, etc.).

En segundo término, el principio general de que cada socio tiene un solo voto hace muy difícil que el socio o socios en conflicto de interés tengan un peso decisivo en la toma de decisiones de la asamblea general. En otras palabras, con toda seguridad serán remotos los casos en que el voto del socio en conflicto de intereses sea determinante para conseguir la mayoría necesaria para aprobar el acuerdo. Esto será particularmente cierto cuanto mayor número de socios tenga la cooperativa (p.ej., no es fácil que en una cooperativa de 100 miembros exista solo un voto de diferencia entre los favorables y los contrarios al acuerdo).

En fin, quizá pudiera presumirse que el socio en conflicto que (indebidamente) vota lo hace en sentido favorable a sus intereses (p.ej., a favor del acuerdo que decide facilitarle asistencia financiera, en contra del acuerdo que pretende excluirle de la sociedad, etc.) y, por tanto, aplicarse la "prueba de resistencia» a partir de esta presunción, que el propio socio podría destruir ${ }^{106}$. De este modo, y salvo esta prueba en contrario, el voto del socio sería sumado a los que han votado en pro de la situación que le beneficia (ya sea favorable o contraria al acuerdo que se propone adoptar), ya que este hecho constituye una presunción razonable que, además, sirve para desincentivar la emisión del voto por el socio y la consiguiente infracción de su

104. Aunque la "prueba de resistencia» ha sido tratada sobre todo en el ámbito de las sociedades de capital, hasta que ha sido reconocida legalmente [art. 204.3.c) y d) LSC], no es dudoso que también se aplica en el caso de las sociedades cooperativas [vid. p.ej., PAZ CANALEJO (1990:449) o BAENA BAENA (2017:199$200 ; 2018: 505)]$.

105. Vid. p.ej., CITROLO (1980:1025), LUMBAU (1990:837), PALLOTTA (2001:223), PALUMNO (2001:1437) o FIMMANÓ (2002:152).

106. En contra, parte de la doctrina italiana, encabezada por NIUTTA (1994:877), que sostiene que no puede presumirse el sentido del voto del socio en conflicto de intereses. 
deber de abstención. En este sentido, el art. 190.3 LSC, en la redacción que le da la Ley 31/2014, de 3 de diciembre, considera que, salvo en los denominados acuerdos posicionales, "cuando el voto del socio o socios incursos en conflicto haya sido decisivo para la adopción del acuerdo, corresponderá, en caso de impugnación, a la sociedady, en su caso, al socio o socios afectados por el conflicto, la carga de la prueba de la conformidad del acuerdo al interés social». 


\section{Bibliografía}

ALFARO ÁGUILA-REAL, J.: "El voto divergente" [Artículo en blog], Almacén de Derecho, 5 febrero, 2018. Recuperado de

https://almacendederecho.org/el-voto-divergente/

ALFONSO SÁNCHEZ, R.: La integración cooperativa y sus técnicas de realización: la cooperativa de segundo grado, Tirant lo Blanch, València, 2002.

- La transformación de la sociedad cooperativa, EDERSA, Madrid, 2002b.

ALONSO ESPINOSA, F.J.: "Órgano de administración»". En: La Sociedad Cooperativa en la ley 27/1999, de 16 de julio, de Cooperativas (coord. ALONSO ESPINOSA, F.J.), Editorial Comares, Granada, 2001, pp. 229-248.

ANGELIS; L. de: "L'intervento del socio nelle assemblee delle società cooperative", Le Società, 2000/7, pp. 803-818.

ASQUINI, A.: "In tema di voto segreto e altre questioni", Giur. Merito, 1970/I, págs. 498-503.

BAENA BAENA, P.J.: Legitimación activa para la impugnación de acuerdos sociales (de la junta general de las sociedades anónimas y de responsabilidad limitada y de la asamblea general de la cooperativa), Marcial Pons, Ediciones Jurídicas y Sociales, Madrid, 2006.

— "La asamblea general: (II) Constitución. Celebración. Impugnación de acuerdos (arts. 30-35 LSCA)". En: Retos y oportunidades de las sociedades cooperativas andaluzas ante su nuevo marco legal (dirs. MORILLAS JARILLO, M.J.; VARGAS VASSEROT, C. \& coord. CANO ORTEGA, C.), Dykinson, Madrid, 2017, pp. 183-238.

— "La asamblea general: (II) Constitución. Celebración. Impugnación de acuerdos", En: Tratado de Derecho de Cooperativas (dir. PEINADO GRACIA, J.I.), Tomo I (2a ed.), Tirant lo Blanch, València, 2018, pp. 482-556.

BALZANO, M.: "Nomina degli amministratori di società cooperativa con voto segreto", Le Società 1997/7, pp. 775-781.

BORJABAD GONZALO, P.: Manual de Derecho Cooperativo. General y Catalán, Jose María Bosch Editor, Barcelona, 1993.

- "La Asamblea General como órgano de mayor participación en la estructura orgánica obligatoria de la sociedad cooperativa catalana y su control jurídico en el anteproyecto de ley de 2014", Anuario Fundación Ciudad de Lleida, 25, 2014, pp. 183-212. 
CAICOYA CORES, J.A.: "(sub) art. 198”. En: Tratado de Sociedades de Capital. Comentario Judicial, Notarial, Registral y Doctrinal de la Ley de Sociedades de Capital (dirs. PRENDES CARRIL, P.; MARTÍNEZ-ECHEVARRÍA Y GARCÍA DE DUEÑAS, A.; CABANAS TREJO, R. \& coord. BALLESTER AZPITARTE, L.), Tomo I, Aranzadi, Madrid, 2017, pp. 1137-1150.

CALAZA LÓPEZ, S.: El proceso de impugnación de acuerdos de las sociedades anónimas y cooperativas, Editorial Universitaria Ramón Areces, Madrid, 2003.

CITROLO, M.: "Sulla votazione a scrutinio segreto nelle assemblee delle società per azione", Vita not., fasc. 4-5, 1980, pp. 1024-1028.

COSTANZA, M. (1989): "Delibere assembleari di spa a scrutinio segreto", Giur. it., 1989/I, pp. 11-12.

ELEJABARRIETA GOIENETXE, A.: “(sub) art. 20”. En: Glosa a la Ley de Cooperativas de Euskadi (dir. PAZ CANALEJO, N.), Consejo Superior de Cooperativas de Euskadi, Vitoria-Gasteiz, 1999, pp. 75-83.

FIMMANÓ, F.: "I sistemi di voto tra autonomía statutaria ed "autodeterminacione" assembleare", Le Società, 2002/6, pp. 697-709.

GADEA SOLER, E.; SACRISTÁN BERGÍA, F. \& VARGAS VASSEROT, C.: La sociedad cooperativa del siglo XXI, Dykinson, Madrid, 2009.

GARCÍA MÁS, F.J.: "De los órganos de la sociedad cooperativa”. En: Cooperativas. Comentarios a la Ley 27/1999 (ed. COLEGIOS NOTARIALES DE ESPAÑA), Tomo I, Colegios Notariales de España, 2001, pp. 133-198.

GENNARI, F.: "Ė valida la deliberazione assembleare che introduce la modalità dello scrutinio segreto?", Le Società, 2003/6, pp. 869-874.

GÓNZALEZ TAUSZ, R.: "Problemas en torno a las asambleas generales de delegados de las cooperativas", La Ley, 1998/4, D-202, pp. 1468-1478.

HENRY, H.: Guide de législation coopérativ ( $3^{\mathrm{a}} \mathrm{ed}$.), Bureau International du Travail, Genève, 2013.

LASSALETTA GARCÍA, P.: "Impugnación de acuerdos del consejo rector en las sociedades cooperativas", Revista de derecho privado, 78(4), 1994, pp. 333-349.

LEONE, G.: "Invalidità della clausola statutaria sul voto segreto in assemblea", $L e$ Società 1997/9, pp. 428-433.

LLUÍS Y NAVAS, J.: Derecho de cooperativas, Tomo I, Librería Bosch, Barcelona, 1972.

LUMBAU, D.: "In tema di esercizio del diritto di voto", Giur. Comm, 17(5), septiembre-octubre, 1990, pp. 825-840. 
MACÍAS RUANO, A.J.: Las sociedades cooperativas y la adaptación de sus principios al mercado, Cajamar Caja Rural, Almería, septiembre, 2016. [http://www.publicacionescajamar.es/pdf/series-tematicas/economia/las-sociedades-cooperativas. pdf].

MASCHIO, E.: "Il punto sulla questione della deliberazione assembleare di società di capitali (e di cooperative) a voto segreto in genere e per la nomina alle cariche sociali in specie", Riv. Soc. 1972, pp. 979-992.

MENÉNDEZ MENÉNDEZ, A.: "El voto divergente en las sociedades de capital". En: Estudios de derecho de sociedades y derecho concursal. Libro homenaje al profesor Rafael García Villaverde, Vol. 2, Marcial Pons, Ediciones Jurídicas y Sociales, Madrid, 2007, pp. 955-968.

MONTAGNANI, C.: “(sub) art. 2368”. En: Società di capitali (dirs. NICCOLINI, G. \& STAGNO D’ALCONTRES, A.), Jovene Editore, Nápoles, 2004, pp. 487 496.

MORILLAS JARILLO, M.J. \& FELIÚ REY, M.I.: Curso de Cooperativas (2a ed.), Editorial Tecnos, Madrid, 2002.

NIUTTA, A.: "La votazione a scrutinio segreto nelle delibere assembleari di società di capitali (e delle società cooperative in particolare)", Giur. Comm. 21(5), septiembre-octubre, 1994, pp. 868-885.

PALLOTTA, E.: "Illegitimità (senza eccezioni) del voto segreto", Le Società, 2001/2, pp. 217-225.

PALUMMO, S.: "Scrutinio segreto ed astensione del socio nell'assemblea", El diritto fallimentare e delle società commerciali, noviembre-diciembre, 2001, pp. 14331443.

PANIAGUA ZURERA, M.: "La sociedad cooperativa. Las sociedades mutuas de seguros y las mutualidades de previsión social”. En: Tratado de Derecho Mercantil, T. XII: La sociedad cooperativa. Las sociedades mutuas y las entidades mutuales. Las sociedades laborales. La sociedad de garantía reciproca (dirs. OLIVENCIA, M; FERNÁNDEZ-NÓVOA, C. \& JIMÉNEZ DE PARGA, R.), Marcial Pons, Ediciones Jurídicas y Sociales, Madrid, 2005, Vol. 1.

PASTOR SEMPERE, C.: “Órgano de administración”. En: Cooperativas agrarias y sociedades agrarias de transformación (dir. PULGAR EZQUERRA, J.), Dykinson, Madrid, 2006, pp. 493-563.

PAZ CANALEJO, N.: "Principales innovaciones de la Ley 3/1987, General de Cooperativas”, Estudios Cooperativos, 54/55, 1986/1987, pp. 11-36.

https://dialnet.unirioja.es/servlet/articulo?codigo $=1148756$

— "La Asamblea General". En: Las sociedades cooperativas en la nueva legislación española, Escuela de Estudios Cooperativos, Madrid, 1988, pp. 21-46. 
— “(sub) art. 49”. En: Comentarios al Código de Comercio y legislación mercantil especial, T. XX: Ley General de Cooperativas, Vol. 2 (dirs. SÁNCHEZ CALERO, F. \& ALBALADEJO, M.), EDERSA, Madrid, 1990, pp. 470-493.

— "(sub) art. 67". En: Comentarios al Código de Comercio y legislación mercantil especial, T. XX: Ley General de Cooperativas, Vol. 3 (dir.: SÁNCHEZ CALERO, F. \& ALBALADEJO, M.), EDERSA, Madrid, 1994, pp. 1-36.

- "Baja del socio cooperador: causas, clases y procedimiento". En: Asociaciones, fundaciones y cooperativas (dir. MARÍN LÓPEZ, J.J.), Consejo General del Poder Judicial (CGPJ), Madrid, 1995, pp. 205-277.

— "La próxima legislación cooperativa madrileña", CIRIEC-España, Revista de Economia Pública, Social y Cooperativa, 29, 1998, pp. 149-164.

- "Perspectivas y problemas jurídicos de la nueva ley estatal de cooperativas", $R E$ VESCO. Revista de Estudios Cooperativos, 69, 1999, pp. 183-198.

PEINADO GRACIA, J.I.: "Constitución e inscripción". En: Tratado de Derecho de Cooperativas (dir. PEINADO GRACIA, J.I. \& coord. VÁZQUEZ RUANO, T.), Vol. I, Tirant lo Blanch, València, 2013, pp. 143-188.

PETRELLI, G.: "Il voto segreto nell'assemblea delle società di capitali e cooperative", Commissione Studi d'Impresa: Studio n. 5630/I, 2005. http://www.gaetanopetrelli.it/catalog/documenti/00000097/2005\%20-\%20Il\%20voto\%20segreto $\% 20$ nell_assemblea $\% 20$ delle $\% 20$ societa $\% 20 \mathrm{di} \% 20$ capitali\% $\% 20 \mathrm{e} \% 20$ cooper ative.pdf.

POMELLI, A.: "I limiti di ammissibilità del voto segreto nelle assemblee di società di capitali e cooperative", Giurisprudenza Commerciale, 29(6), noviembre-diciembre, 2002, pp. 683-714.

RODRÍGUEZ SÁNCHEZ, S.: "La asamblea general en la Ley 27/1999, de 16 de julio, de cooperativas: algunas reflexiones", Revista de Derecho de Sociedades (RdS), 17, 2001, pp. 247-266.

SACRISTÁN BERGIA, F.: "La asamblea general en el marco de las cooperativas agrarias y de las sociedades agrarias de transformación”. En: Cooperativas agrarias y sociedades agrarias de transformación (dir. PULGAR EZQUERRA, J. \& coord. VARGAS VASSEROT, C.), Dykinson, Madrid, 2007a, pp. 463-492.

— "El régimen del proceso disolutorio extintivo de las sociedades cooperativas agrarias y las sociedades agrarias de transformación”. En: Cooperativas agrarias y sociedades agrarias de transformación (dir. PULGAR EZQUERRA, J. \& coord. VARGAS VASSEROT, C.), Dykinson, Madrid, 2007b, pp. 821-863.

SALVATORE, L.: "Voto segreto e banche di credito cooperativo", Contratto e impresa, 2001, pp. 821-839. 
SÁNCHEZ RUIZ, M.: “Asamblea General”. En: La Sociedad Cooperativa en la ley 27/1999, de 16 de julio, de Cooperativas (coord. ALONSO ESPINOSA, F.J.), Editorial Comares, Granada, 2001, pp. 197-228.

SÁNCHEZ-CALERO GUILARTE, J.: "La propuesta de generalización del voto divergente". En: Estudios jurídicos en homenaje al profesor Manuel García Amigo (dirs. CUADRADO IGLESIAS, M. \& NÚNEZ BOLUDA, M.D.), Tomo II, La Ley, Madrid, 2015, pp. 2143-2178.

SANTOS DOMINGUEZ, M.Á.: El poder de decisión del socio en las sociedades cooperativas: la asamblea general, Editorial Civitas, Pamplona, 2014.

SCORDINO, F.: La società cooperativa, Jovene Editore, Nápoles, 1970.

SEDA HERMOSÍN, M.A.: "Capítulo V. Órganos sociales". En: Comentarios a la Ley de Sociedades Cooperativas Andaluzas. Ley 2/1999, de 31 de marzo (coords. ROMERO CANDAU, P.A. \& SUÁREZ PALOMARES, E.), CEPES. Confederación Empresarial Española de la Economía Social, Madrid, 2002, pp. 345-537.

SENENT VIDAL, M.J.: La impugnació del acords socials de la cooperativa [Tesis doctoral, Universitat Jaume I], Castelló de la Plana, 2003.

TASSINARI, F.: "Il voto segreto nelle assemblee di società", Giurisprudenza Commerciale, 21(3), mayo-junio, 1994, pp. 495-502.

UCELAY URECH, I.: "El abuso del derecho por socios de cooperativas", Diario La Ley, 1997/4, D-228, 1997, pp. 1349-1359.

URÍA, R.; MENÉNDEZ, A. \& MUÑOZ PLANAS, J.M.: "La junta general de accionistas". En: Comentario al régimen legal de las sociedades mercantiles (dirs. URÍA, R.; MENÉNDEZ, A. \& OLIVENCIA, M.), Editorial Civitas, Pamplona, 1992, Tomo $\mathrm{V}$.

VARGAS VASSEROT, C.; GADEA SOLER, E. \& SACRISTÁN BERGIA, F.: Derecho de las sociedades cooperativas, Volumen 1: Introducción, constitución, estatuto del socio y órganos sociales, La Ley, Madrid, 2015.

VICENT CHULIÁ, F.: "La asamblea general de la cooperativa", Revista Jurídica de Catalunya. 77(2), 1978, pp. 417-495.

— "El derecho de los órganos sociales desde la perspectiva de la legislación cooperativa", Revista de Derecho Mercantil (RDM), 153/154, 1979, pp. 483-590.

— "(sub) art. 56". En: Comentarios al Código de Comercio y legislación mercantil especial, T. XX: Ley General de Cooperativas, Vol. 2 (dirs. SÁNCHEZ CALERO, F. \& ALBALADEJO, M.), EDERSA, Madrid, 1990, pp. 684-703. 